\title{
THE EFFECT OF BEHAVIORAL BIASES ON FINANCIAL DECISIONS ${ }^{\star}$ \\ EL EFECTO DE LOS SESGOS DE COMPORTAMIENTO EN LAS DECISIONES FINANCIERAS
}

Received: December 2020

Evaluated: February 2021

Approved: May 2021

\author{
David Peón ${ }^{\star *}$ \\ University of A Coruna, Spain \\ Orcid: https://orcid.org/0000-0002-5212-4385 \\ Manel Antelo ${ }^{\star \star \star}$ \\ University of Santiago de Compostela, Spain \\ Orcid: https://orcid.org/0000-0003-1846-6872
}

How to cite this article: Peón, D. y Antelo, M. (2021). The effect of behavioral biases on financial decisions.

Revista Estrategia Organizacional, 10(2), https://doi.org/10.22490/25392786.4963

* Research article

** Department of Financial Economics and Accountancy. University of A Coruna, Campus de Elviña s/n, 15071 A Coruña (Spain).

*** Department of Economics, University of Santiago de Compostela, Campus Norte s/n, 15789 Santiago de Compostela (Spain) 


\begin{abstract}
Financial management decisions are made by people, and people, in all instances, are shaped by their behavioral traits. Here we provide extensive insight on the theoretical and empirical analysis made on cognitive biases and their influence on financial decisions. To provide a systematic exposition, we set three broad categories: heuristics and biases, choices (including framing and preferences) and social factors. We then describe the main biases within each category and provide an extensive revision of the main theoretical and empirical developments about their impact on financial decisions.
\end{abstract}

Keywords: Behavioral biases, decision-making, heuristics, framing, prospect theory, social contagion, management.

\title{
RESUMEN
}

Las decisiones de gestión financiera las toman las personas, y las personas, en todos los casos, están determinadas por sus rasgos de comportamiento. Aquí proporcionamos una visión amplia del análisis teórico y empírico realizado sobre los sesgos cognitivos y su influencia en las decisiones financieras. Para proporcionar una exposición sistemática, establecemos tres categorías amplias: heurísticas y sesgos, elecciones (incluidos encuadres y preferencias) y factores sociales. A continuación, describimos los principales sesgos dentro de cada categoría y proporcionamos una revisión exhaustiva de los principales desarrollos teóricos y empíricos sobre su impacto en las decisiones financieras.

Palabras clave: sesgos de comportamiento, toma de decisiones, heurística, encuadre, teoría prospectiva, contagio social, administración. 


\section{INTRODUCTION}

The standard model of rational choice argues that people choose to follow the option that maximizes expected utility. Although this estimate can be difficult to do, the theory assumes people make it well. However, it ignores the presence of behavioral biases; i.e., the tendency to reason in certain ways that can lead to systematic errors or deviations from a standard of rationality or good judgment in thinking or reasoning (Shefrin, 2006).

Both psychology and behavioral economics have provided extensive evidence that people are vulnerable to biases and use shortcuts in thinking, exhibit biases in decision-making, tend to frame their decisions, exhibit preference reversals and struggle to commit to their past decisions, they are influenced by others' behaviors, etc. Thus, non-standard preferences, beliefs, biases, and decision-making may lead to an unconventional behavior (DellaVigna, 2009), in terms of the anomalies and decision effects they carry on; that is, empirical results that are difficult to rationalize within the paradigm (Khaneman, Knetsch and Thaler, 1991). Bounded rationality (Simon, 1957) has replaced a completely rational model of choice. The more realistic our assumptions about the economic agents, the better our explanations and predictions will be (Rabin, 2002a).

Here we survey the main biases identified in behavioral economics and finance, separating them from their behavioral consequences. The literature is so vast that trying to cover them all here in detail would be unfeasible. Hence, we contribute in three instances. First, we start by providing a taxonomy that is based on the reviews of relevant authors in the field. We then describe the most significant of those biases and review the main contributions in terms of antecedents, theoretical, empirical and experimental developments, and recent literature. Finally, we relate these biases with other biases and anomalies that are linked to them, according to the literature.

The remainder of the article is laid out as follows: Section 2 provides a novel taxonomy of biases classified in three groups; Section 3 reviews the main heuristics and judgmental biases; Section 4 is dedicated to choices (framing and preferences); Section 5 surveys the main social factors; Section 6 concludes the article. 


\section{SEARCHING FOR A TAXONOMY OF BIASES}

Many authors have provided different taxonomies of the most relevant behavioral biases, but rarely using a comprehensive approach. The fact that the classification rules are diverse, and that different authors often use different names for similar concepts, makes it difficult to provide an inclusive classification satisfying all criteria. To circumvent these limitations, we offer a taxonomy that blends some relevant reviews. They follow in order.

Kahneman, Slovic and Tversky (1982) summarize heuristics and biases in seven categories: representativeness, causality and attribution, availability, covariation and control, overconfidence, conservatism, and judgmental biases in risk perception. Gigerenzer (1991) cites a list of biases, fallacies and errors in probabilistic reasoning (e.g., conjunction fallacy) and explains them in terms of cognitive heuristics (e.g., representativeness). Tversky and Kahneman (1992) list five major phenomena: framing effects, nonlinear preferences, source dependence, risk seeking and loss aversion. Plous (1993) separates perception, memory, and context; heuristics and biases; how questions affect answers; models of decision-making; the social side of judgment and decisionmaking; and common traps. Kahneman and Riepe (1998) classify deviations from rationality in three categories: heuristics, errors of preference (prospect theory and loss aversion), and framing.

Rabin (1998) distinguishes mild biases (e.g., reference level and loss aversion), severe biases in judgment under uncertainty (e.g., confirmatory bias) and psychological findings that imply a radical critique of the maximizing utility model (framing effects, preference reversals, and selfcontrol). Belsky and Gilovich (1999) highlight misconceptions of chance and probability, mental accounting, loss aversion, anchoring, confirmation bias, overconfidence, and emotional biases (in the 2009 edition). Shiller (2000a) lists theories from social sciences used in finance, including prospect theory, regret and cognitive dissonance, representativeness, mental accounting, and overconfidence. Mullainathan and Thaler (2000) note three ways humans deviate from the standard economic model (bounded rationality, bounded willpower and bounded self-interest). Gilovich and Griffin (2002) list six general purpose heuristics (affect, availability, causality, fluency, similarity and surprise) and six special purpose heuristics (attribution substitution, outrage, prototype, recognition, choosing by liking and choosing by default). 
Barberis and Thaler (2003) label beliefs (e.g., representativeness) and preferences (prospect theory and ambiguity aversion). Camerer and Loewenstein (2004) list probability judgments (e.g., heuristics) and preferences (framing, anchoring, loss aversion, reference dependence, preference reversals, and hyperbolic time discounting). Hens and Bachmann (2008) distinguish five types of heuristics: information selection biases, information processing biases, decision biases, decision evaluation biases, and biases in intertemporal decisions. Akerlof and Shiller (2009) note five aspects of animal spirits, including feedback mechanisms, attitudes about fairness, and social contagion. DellaVigna (2009) separates non-standard preferences, non-standard beliefs, and non-standard decision-making. Finally, recent surveys separate investor beliefs and preferences (Sahi, Arora and Dhameja, 2013), sources of judgment and decision biases (Hirshleifer, 2015).

Following the above, our taxonomy separates three categories: heuristics and judgmental biases, choices (framing and preferences), and social factors. We have firstly followed the spirit of Kahneman and Tversky's work, which distinguishes (i) the heuristics that people use and the biases to which they are prone when judging in an uncertain context, (ii) the prospect theory, as a model of choice under risk, and loss aversion in riskless choice, and (iii) the framing effects (Kahneman, 2003a,b). Secondly, we merged framing and prospect theory (preferences, broadly speaking) in a single category of choices. We do this following Tversky and Kahneman (1981), who consider two phases in the choice process - an initial of framing and a subsequent of evaluation-, and Barberis and Huang (2009), who suggest framing and prospect theory form 'a natural pair'. Indeed, though framing may be seen as a heuristic error since it assumes bounded rationality, Rabin (1998) considers framing effects more relevant because they may determine an individual's preferences. Finally, we include a third category with those biases people make influenced by other people. We denote this group as social factors, which refer to cultural and social influences on an individual's behavior. Shiller (2000a), Shefrin (2000), and Hens and Bachmann (2008), among others, advocate for this category.

\section{HEURISTICS AND JUDGMENTAL BIASES}

Heuristics refer to economical shortcuts for information processing, or simple rules that ignore information (Marewski, Gaissmaier and Gigerenzer, 2010). Since information is vast, disperse, changes continuously and its gathering is costly, people develop rules of thumb to make decisions, often leading them to make some errors (Shefrin, 2000). Griffin et al. (2012) provide a historical 
overview. In its initial conception, heuristics were restricted to the domain of judgment under uncertainty, a scope later broadened (Kahneman and Frederick, 2002) to a variety of fields that share a common process of attribute substitution. In other words, "difficult judgments are made by substituting conceptually or semantically related assessments that are simpler and more readily accessible" (Kahneman and Frederick, 2005, p. 287).

Much research has been performed to investigate whether and when people rely on heuristics (e.g. Cokely and Kelley, 2009; Hoppe and Kusterer, 2011), when do heuristics perform well (e.g. Gigerenzer and Goldstein, 1996) or how accurate they are for predicting uncertain events, such as stock prices (e.g. Ortmann et al., 2008). Moreover, Lacetera, Pope and Sydnor (2014) show information-processing heuristics matter even in markets with easily observed information. However, two contrary views prevail among researchers. On one hand, authors like Gigerenzer and Gaissmaier (2011) argue that heuristics are efficient shortcuts for inference unless empirically shown otherwise. They would be adaptive strategies that evolved in tandem with fundamental psychological mechanisms (Goldstein and Gigerenzer, 2002). No rule is assumed to be rational per se; what matters is to understand when a given heuristic performs better - a concept named ecological rationality.

On the other hand, other authors identify two cognitive systems, reason and intuition, being the latter the norm. In these dual-process theories (Kahneman and Frederick, 2005), heuristics would be the fast, intuitive, affect-driven and effortless cognitive system, as opposed to the slow, controlled and analytical of reasoning. Heuristics can be powerful and accurate, but when misapplied can cause big mistakes (Hirshleifer, 2008). While judgments are intentional, intuition generates spontaneous and involuntary impressions that depend on their accessibility -the ease with which thoughts come to mind. Through the process of attribution substitution, a target attribute of the judged object is substituted by a heuristic attribute. Since the target and heuristic attributes are different, the change induces systematic errors in judgment and decision, known as judgmental biases.

In Table 1 we collect some relevant heuristics and judgmental biases. Both concepts specify how agents form expectations, and consequently they are sometimes merged. Nonetheless, most authors - e.g., the original approach by Tversky and Kahneman (1974) - consider first the heuristics people use and then the biases they lead to. Hence, we proceed separately with the analysis of each heuristic and the judgmental biases associated with each of them. 


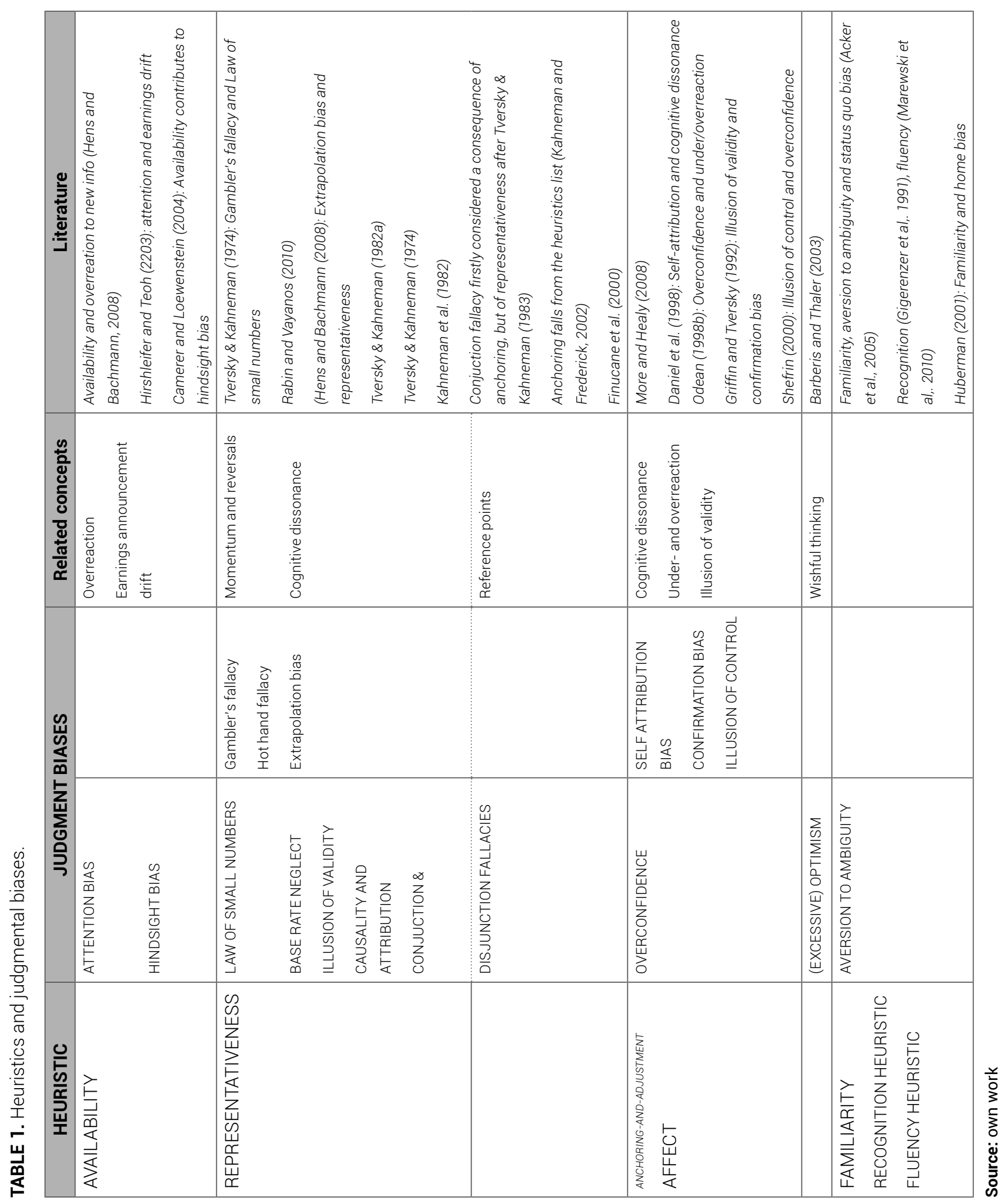




\subsection{AVAILABILITY HEURISTIC}

Availability is the most important information selection bias (Hens and Bachmann, 2008), and refers to the tendency to estimate the probability of an event by the ease with which occurrences can be brought to mind (Tversky and Kahneman, 1973). Due to our limited attention, memory and processing capacities, we make decisions based on subsets of information that are easily available. This is a useful shortcut to assess probability because instances of large classes are better recalled. However, it may lead to several biases as it is affected by factors other than frequency, such as imagination, familiarity and salience.

Early papers include Ross and Sicoly (1977), Taylor (1982), and Kahneman and Tversky (1982), who identify the simulation heuristic, a mental operation that explains how the availability heuristic works. Heath, Larrick and Klayman (1998) argue its effects are ubiquitous because of a lack of experience with unusual events. Recent research shows its effect on social media (Chou and Edge, 2012). The availability heuristic contributes to attention anomalies, the hindsight bias, an overreaction to new information (Hens and Bachmann, 2008), and the curse of knowledge, whereby people who know much are not aware of how little others know (Camerer and Loewenstein, 2004).

Attention bias Attention is a scarce resource and our ability to process information is limited, so previous to decision making we must select which options to analyze. If the attributes that catch our attention are not critical, it may lead to suboptimal choices. Barber and Odean (2008) note three indicators of attention for stock investors. Odean (1999) suggests that the bias, together with overconfidence and the disposition effect, explain the excessive trading in financial markets. Hirshleifer and Teoh (2003) show that limited attention to how information is displayed in financial reports may explain the post-earnings announcement drift. Recent literature includes Battalio et al. (2012) and Hirshleifer, Hou and Teoh (2012) on the accruals anomaly.

Hindsight bias Human memory has a limited capacity, so it works by reconstruction. Hindsight bias results as a side-effect: once we known the outcome of an event, our recalled judgments are typically closer to the outcome than our first judgments were (Hoffrage, Hertwing and Gigerenzer, 2000). Thus, in hindsight, we exaggerate what we might have anticipated in foresight (Fischhoff, 1982). The availability heuristic contributes to this bias because events that occurred are easier 
to imagine than counterfactual ones (Camerer and Loewenstein, 2004). Biases in hindsight would explain overconfidence (Fischhoff, 1982) and amplified regret (Pan and Statman, 2010). Recent research includes Roese and Vohs (2012) and Chelley-Steeley, Kluger and Steeley (2015).

\subsection{REPRESENTATIVENESS HEURISTIC}

Tversky and Kahneman (1983) define representativeness as the degree of correspondence between an outcome and a model. In short, we infer the probability that an object A belongs to class $B$, or that it originates from it, by evaluating the degree to which $A$ is representative of $B$ (Tversky and Kahneman, 1974). A tendency to rely on stereotypes, it leads to estimating probabilities based on beliefs rather than probability (Shleifer, 2000). Early research addressed the determinants of representativeness (Kahneman and Tversky, 1972) and experimental evidence (Tversky and Kahneman, 1973). Models include Barberis, Shleifer and Vishny (1998), who suggest investors forecast future earnings interpreting past earnings using the heuristic, and Gennaioli and Shleifer (2010), who provide a memory-based model of probabilistic inference. Recent research analyzes the presence of representativeness (Alós-Ferrer and Hügelschäfer, 2012) and its effect on public policy (Briley, Shrum and Wyer, 2013), among others. Finally, representativeness leads to several biases of judgment under uncertainty. Next, we see some of them.

Law of small numbers People have strong intuitions about random sampling. One intuition refers to the tendency to exaggerate how closely a small sample will resemble the parent population (Tversky and Kahneman, 1971). A bias related to representativeness and the tendency to underuse base rates (Tversky and Kahneman, 1974), it leads to gambler's fallacy and misperception of regression to the mean (Rabin, 1998), and a belief in the hot hand fallacy. Rabin (2002b) develops a model that explains the empirical finding of short-term underreaction but medium-term overreaction to announcements in stock markets.

Gambler's fallacy A consequence of misconceptions of chance, this fallacy conveys the belief that random sequences should exhibit systematic reversals (Rabin and Vayanos, 2010) and the tendency to see patterns in truly random sequences (Barberis et al., 1998). Huber, Kirchler and Stöckl (2010) obtain experimental evidence of its effect in investment decisions. Suetens and Tyran (2012) observe that men exhibit this fallacy, while Stöckl et al. (2015) obtain experimental evidence that women are prone to display a hot hand fallacy. 
Hot hand fallacy This fallacy arises when one predicts long streaks of similar signals will continue (Rabin and Vayanos, 2010). Like the gambler's fallacy, it implies a failure to appreciate statistical independence, but involves instead the belief in an excessive persistence rather than reversals. Nonetheless, some authors (e.g., Rabin, 2002b) suggest the latter may arise as a consequence of the former. Both fallacies would explain financial puzzles such as momentum and reversals in asset returns (Rabin and Vayanos, 2010). The hot hand fallacy is also related to the hot hands effect: mutual funds that performed well one year continued to outperform the next one (Hendricks, Patel and Zeckhauser, 1993).

Extrapolation bias Caused by representativeness, the extrapolation bias suggests that people bet on trends (Shefrin, 2000). Tversky and Kahneman (1973) were the first to provide experimental evidence, while empirical evidence includes Benartzi (2001), who shows that employees tend to buy stocks of the company for which they work after prices had already gone up. Its presence may lead to either over or underreaction.

Base rate neglect Tversky and Kahneman (1974) noticed that prior probabilities (base-rate frequencies) play a key role in probability assessment but none on representativeness. This implies a base rate bias, i.e., an insensitivity to prior probability of outcomes. Prendergast and Stole (1996) relate it to cognitive dissonance reduction: individuals overweigh their own information. Although it received the most attention in social psychology among all cognitive illusions (Gigerenzer, 1991), the base rate neglect remains a controversial bias. First, it seems in contradiction to the widespread belief that judgments are affected by stereotypes (Landman and Manis, 1983). Second, there is the debate already mentioned about whether heuristics are efficient shortcuts or not. In particular, questions in Tversky and Kahneman (1982a)'s experimental research were rephrased in a frequentist way by Cosmides and Tooby (1990), and the base-rate fallacy disappeared. Kahneman and Tversky (1996) replied they ignore critical evidence that judgments of frequency are susceptible to systematic biases. Recent contributions include Pennycook and Thompson (2012) and Pennycook et al. (2014).

Illusion of validity People tend to select the outcome that is most representative of the input and, in doing so, the confidence they have in their prediction depends on the degree of representativeness (Tversky and Kahneman, 1974). A sort of confirmation bias leading to 
overconfidence (Shefrin, 2000), the illusion of validity tends to persist even when we are aware of the factors that limit the accuracy of our predictions. Einhorn and Hogarth (1978) suggest we exhibit the bias because we search for confirming evidence. Recent research includes Ilomäki (2012), who observes this bias among stock market professionals.

Causality and attribution When people attempt to infer the causes of the effects observed, they may incur in errors related to salience, availability, representativeness, egocentric biases and others. Early research is listed in Kahneman et al. (1982). Attribution theory by Weiner (1985) provides the principles underlying the process of causal thinking. Gurevich, Kliger and Weiner (2012) explore how perceived causes for a gain affect economic decisions. Causal attribution extends to groups as well, causing scapegoating and xenophobia (Hirshleifer, 2008).

Conjunction and disjunction fallacies A conjunction fallacy appears when people believe the probability of a conjunction of two events is greater than that of one of its constituents. Related to it is the disjunction fallacy, i.e. the probability of an event $A$ must be equal to the probability of all events whose union is equal to $A$, but subjects often underestimate the residual hypotheses. BarHillel (1973) set an antecedent, though the conjunction fallacy is original of Tversky and Kahneman (1982b) and their classic Linda experiment. Recent research includes Liberali et al. (2012) and Oechssler, Roider and Schmitz (2009), who use Frederick's (2005) test to show lower cognitive reflection correlates with a higher conjunction fallacy, models by Gennaioli and Shleifer (2010), and experimental tests of their effects on markets by Rieger (2012) and Erceg and Galic (2014).

\subsection{AFFECT HEURISTIC}

Although we included the conjunction and disjunction fallacies as consequences of the representativeness heuristic, this is not the original view. Tversky and Kahneman (1974) suggested they are induced by anchoring: the stated probability of the simple event provides a natural starting point to estimate the probabilities of both conjunctive and disjunctive events. Later, Tversky and Kahneman (1983) would see them as induced by representativeness: judgments are based on the similarity between the description of Linda and the alternatives. This change in criteria is due to attribution substitution, a concept developed by Kahneman and Frederick (2002) that modified the list of heuristics in consequence. On one hand, anchoring did not fit the definition of a heuristic anymore, as it does not work through the substitution of one attribute for another. Ever since, most 
authors (e.g., Camerer and Loewenstein, 2004) classify anchoring-and-adjustment as an error of preference that derives from the existence of reference points (see Section 4). On the other hand, it put the affect heuristic (Finucane et al., 2000) on the list.

Affect is a natural assessment, automatically computed and always accessible, so the basic evaluative attribute (e.g., good/bad, like/dislike) is a candidate for substitution in any task that calls for a favorable or unfavorable response. Representations of objects and events in our minds are tagged to varying degrees with affect. Then, the affect heuristic would be the reliance on such feelings to make judgments, which may provide faster and more efficient intuitions than retrieving some examples from memory. Failing to identify the affect heuristic, as stated by Kahneman and Frederick (2002), "reflects the narrowly cognitive focus that characterized psychology for some decades. There is now compelling evidence that every stimulus evokes an affective evaluation" (p. 55), conscious or not.

The concept of attribution substitution contributed to the development of heuristic elicitation. Traditionally, heuristics were studied by examining biases from normative rules, but attribution substitution allows direct tests: one group of respondents judge a target attribute for a set of objects, while another evaluates the hypothesized heuristic attribute. Loewenstein et al. (2001) propose an alternative to the cognitive theories of choice under risk to date, the so-called model of risk-as-feelings. It emphasizes the role of affect in decision-making: beliefs about risk would be expressions of emotion that often diverge from cognitive assessments. Slovic et al. (2002) introduce a theoretical framework where affect would be the heuristic attribute for numerous target attributes, in common with the model of risk-as-feelings. Recent contributions include both the theoretical (Haack, Pfarrer and Scherer, 2014) and experimental (Pachur and Galesic, 2013; Jaspersen and Aseervatham, 2015).

\subsection{OVERCONFIDENCE}

Overconfidence, the human tendency to overestimate our own skills and predictions for success (Ricciardi and Simon, 2000), is one of the most relevant heuristic-driven biases that entails a miscalibration of subjective probabilities. Following Lichtenstein and Fischhoff (1977), a judge is well-calibrated if "over the long run, for all propositions assigned the same probability, the proportion true is equal to the probability assigned" (p. 161). However, early research (e.g., Oskamp, 1965) 
showed people to be poorly calibrated, and later research (e.g. survey by Griffin and Brenner, 2004) confirmed the results. However, overconfidence may refer to different concepts. Moore and Healy (2008) identify three: overestimation in estimating our own performance, overplacement or betterthan-average effect (Williams and Gilovich, 2008) in estimating our own performance relative to others, and overprecision, an excessive precision to estimate future uncertainty (e.g., Alpert and Raifa, 1969).

Researchers suggest men are more overconfident than women. Lundeberg, Fox and Punccohar (1994) show it happens particularly in tasks perceived to be masculine, like financial topics (Prince, 1993), and Barber and Odean (2001) observe men trade more frequently and exhibit more losses. Recent tests include Biais et al. (2005) and Grinblatt and Keloharju (2009) on effects on trading, Grieco and Hogarth (2009) on overestimation and overplacement, and Chen et al. (2007) on cultural differences. Many models in finance are based on overconfidence, including Daniel, Hirshleifer and Subrahmanyam (1998) on over and underreaction, Scheinkman and Xiong (2003) on asset bubbles, and Odean (1998b) on excessive trading volume -Odean (1999) and Statman, Thorley and Vorkink (2006) provide evidence on the latter. Finally, research on managerial overconfidence is a classic as well. Overconfidence causing excessive business entry was already in the hubris hypothesis by Roll (1986), and Camerer and Lovallo (1999) tested it. Malmendier and Tate (2005a,b) obtained similar results linking managerial overconfidence to the high rates of corporate M\&As. Surveys available are Shefrin (2006) and Baker, Ruback and Wurgler (2007).

Overconfidence has shown pervasive effects. Thus, in addition to anomalies such as return predictability, excess volatility, and excessive trading (Hirshleifer, 2001), it would help explain the forward premium puzzle (Burnside et al., 2011), and sensation seeking (Grinblatt and Keloharju, 2009). The connection to other biases is analyzed next.

Self-attribution bias According to Bem (1965), individuals tend to attribute to their ability those events that validate their actions, while attributing contrary evidence to external noise or sabotage. Daniel et al. (1998) relates it to cognitive dissonance, and Statman et al. (2006) observe its impact on investor's overconfidence. Some anomalies attributed to be a consequence of a biased selfattribution are feedback effects that may cause over and underreaction (Daniel et al., 1998), 
and the spread of stories that is essential in the formation of speculative bubbles (Shiller, 2003). Recent literature includes Libby and Rennekamp (2012) and Troye and Supphellen (2012).

Confirmation bias Once they formed a strong hypothesis, people pay attention to news that supports their views while they ignore those that contradict them (Rabin, 1998; Shefrin, 2006). It may be a form of anchoring: people tend to accept confirming evidence for their priors (Lord, Ross and Lepper, 1979). It does not necessarily imply people misinterpret evidence, but that they ignore it or tend to misread evidence as support for their hypothesis (Rabin and Schrag, 1999). Empirical tests include Lord et al. (1979) on capital punishment, Plous (1991) on safety of nuclear technology, and Duong, Pescetto and Santamaria (2014) on investors' use of financial information. Griffin and Tversky (1992) and Rabin and Schrag (1999) link the illusion of validity to confirmation bias to induce overconfidence. The bias might also lead to social rigidity (Hoff and Stiglitz, 2010); since convictions change slowly due to confirmation bias, collective actions also change slowly.

Illusion of control Langer (1975) defines it as people behaving as though chance events were subject to their control. That is, we judge an outcome as a consequence of our acts when in fact we were just lucky. Ji, Nisbett and Su (2001) find Americans believe in stability of events so they think things are more predictable than they really are, explaining why they exhibit illusion of control, as reported in Presson and Benassi (1996) and others. Recent research includes Cowley, Briley and Farrell (2015).

\section{5. (EXCESSIVE) OPTIMISM}

Kahneman and Riepe (1998) describe those individuals who underestimate the likelihood of bad outcomes over which they have no control as optimists. Shefrin (2006) suggests they both overestimate favorable outcomes and underestimate unfavorable ones. Company managers are a classic example, whose optimism would result from cognitive biases and organizational pressures (Lovallo and Kahneman, 2003). Large capital investments, M\&As and efforts to access new markets are situations where optimism pervades in managers' decisions, explaining the high rates of failure observed.

Overoptimism is related to biases such as self-attribution (Lovallo and Kahneman, 2003), overconfidence, groupthink, and wishful thinking (Barberis and Thaler, 2003). In addition, Bracha 
and Brown (2012) provide a theory of optimism bias that relates it to the affect heuristic. Cowen, Groysberg and Healy (2006) offer a measure of forecast optimism by market analysts, and suggest that trading incentives affect their bias. Moreover, Jacobsen et al. (2014) observe men tend to be significantly more optimistic than women in financial markets. Recent research uses excessive optimism as a key factor behind credit booms (Peón, Antelo and Calvo, 2015), and observes a similar bias in governments' official forecasts (Frankel and Schreger, 2013).

\subsection{FAMILIARITY}

The familiarity bias is related to the evidence that people fear change and the unknown (Cao et al., 2011), the ambiguity aversion (Ackert et al., 2005), the recognition heuristic (Gigerenzer, Hoffrage and Kleinbölting, 1991), and the fluency heuristic (Marewski et al., 2010). In addition, it would help explain decision effects such as the status quo bias (Ackert et al., 2005), underdiversification (Boyle et al., 2012) and home and local biases (Huberman, 2001; Pool, Stoffman and Yonker, 2012; Seiler et al., 2013). Moreover, Du and Shelley (2014) obtain experimental evidence of its role on investment behavior. Recent research also includes neurogenetic studies (Chew, Ebstein and Zhong, 2012).

Aversion to ambiguity Ambiguity is the uncertainty about uncertainties (Einhorn and Hogarth, 1986). Then, the aversion to ambiguity describes a preference for 'known' over 'unknown' risks, as shown in the Ellsberg paradox (Thaler, 1983). Early papers include Fellner (1961), who introduced the concept of decision weights. Epstein and Schneider (2010) review models of ambiguity aversion and their implications for portfolio choice and asset pricing. Nonetheless, the opposite result - people preferring ambiguous alternatives- may be obtained in some cases. Thus, Einhorn and Hogarth (1986) specify some conditions for ambiguity seeking and avoidance, while Roca, Hogarth and Maule (2006) show that the status quo bias could lead to ambiguity seeking. Etner, Jeleva and Tallon (2012) provide a review on advances in the field. Recent articles include Alary, Gollier and Treich (2013) on insurance, and Füllbrunn, Rau and Weitzel (2014) on experimental asset markets.

Recognition heuristic Two processes govern this heuristic, recognition and evaluation. Recognition is the capacity to make inferences in cases of limited knowledge (Goldstein and Gigerenzer, 2002): "If one of two objects is recognized and the other is not, recognition heuristic 
infers that the recognized object has the higher value with respect to the criterion" (p. 75). Evaluation judges the heuristic as ecologically rational whenever the recognition validity for a given criterion is much higher than chance. The most frugal of all heuristics (Goldstein and Gigerenzer, 1999), it allows people to benefit from ignorance by making inferences from patterns of missing knowledge. Proposed as a model of inferences made from memory (Gigerenzer and Goldstein, 1996), it is related to familiarity as it implies a probabilistic cue (Gigerenzer et al., 1991). Schooler and Hertwig (2005) pose the notion of beneficial forgetting: loss of information aids inference heuristics that exploit mnemonic information. Goldstein and Gigerenzer (2002) claim that when ignorance is systematically distributed, recognition and criterion are correlated and the heuristic leads to efficient results. Ortmann et al. (2008) analyze how the heuristic performs in portfolio management, with mixed results. Gigerenzer and Goldstein (2011) survey the literature.

Fluency heuristic The recognition heuristic is binary, that is, an alternative is either recognized or not. However, it does not help when two alternatives are recognized but one more strongly than the other. Fluency heuristic fills this gap: if one alternative is recognized faster than another, the fluency heuristic infers the one that has the higher value on the criterion (Schooler and Hertwig, 2005). Schwikert and Curran (2014) analyze the memory processes that contribute to the recognition and fluency heuristics.

\section{CHOICES: FRAMING AND PREFERENCES}

The second group of behavioral biases falls under the category of choices. Tversky and Kahneman $(1981,1992)$ consider two phases in the choice process, an initial of framing and a subsequent of evaluation. Thus, this category includes the following set of items.

Firstly, framing and the biases related to it. Behaviorists have shown that people do not choose in a comprehensively inclusive context as the rational-agent model predicts. In particular, an essential aspect of rationality is invariance, i.e. the fact that preferences are not affected by inconsequential variations in the description of outcomes (Kahneman, 2003a). However, invariance is violated in framing, because alternative descriptions lead to different choices only by altering the salience of different features in the problem. Framing effects include a variety of biases related to two classics in the literature: frame dependence and mental accounting (Thaler, 1985). 
Secondly, prospect theory (Kahneman and Tversky, 1979), a descriptive theory of choice that explains how individuals evaluate the outcomes of risky prospects and choose in consequence. Thirdly, the empirical evidence that people make inconsistent choices when they make decisions over time led to the literature on intertemporal preferences, which started with problems of selfcontrol in intertemporal choice (Thaler and Shefrin, 1981). Framing, prospect theory, intertemporal preferences, and the biases related to them are listed in Table 2, and reviewed below.

TABLE 2. Choices: Framing and preferences.

\begin{tabular}{|c|c|c|c|c|}
\hline \multicolumn{3}{|c|}{ FRAMING \& PREFERENCES } & Related concepts & Literature \\
\hline \multirow[t]{2}{*}{ 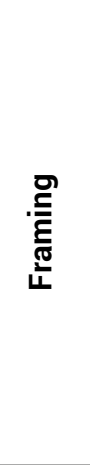 } & FRAME DEPENDENCE & $\begin{array}{l}\text { Narrow framing } \\
\text { Context dependence } \\
\text { Repeated gambles }\end{array}$ & $\begin{array}{l}\text { Equity premium puzzle } \\
\text { Loss aversion } \\
\text { Money illusion }\end{array}$ & $\begin{array}{l}\text { Barberis and Huang (2207): Narrow framing, equity } \\
\text { premium puzzle } \\
\text { Tversky \& Kahneman (1986) } \\
\text { Kahneman et al. (1986a) } \\
\text { Simonson and Tversky (1992) } \\
\text { Kahneman and Riepe (1998) }\end{array}$ \\
\hline & MENTAL ACCOUNTING & $\begin{array}{l}\text { Hedonic editing } \\
\text { Choice bracketing }\end{array}$ & House money effect & $\begin{array}{l}\text { Thaler (1999) } \\
\text { Thaler and Shefrin (1981) } \\
\text { Choice bracketing (Read et al. 1999) }\end{array}$ \\
\hline 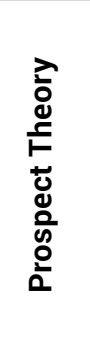 & $\begin{array}{l}\text { REFERENCE } \\
\text { DEPENDENCE } \\
\text { LOSS AVERSION } \\
\text { DIMINISHING } \\
\text { SENSITIVITY }\end{array}$ & $\begin{array}{l}\text { ANCHORING-AND- } \\
\text { ADJUSTMENT } \\
\text { Myopic loss aversion } \\
\text { Risk seeking }\end{array}$ & $\begin{array}{l}\text { Conservatism } \\
\text { Aversion to asume loss } \\
\text { Favorite longshot bias }\end{array}$ & $\begin{array}{l}\text { Anchoring not heuristic, related to reference points } \\
\text { (Robin, 1998) } \\
\text { Conservatism: Chan et al. (1996) } \\
\text { Benartzi and Thaler (1995) } \\
\text { Shefrin (2006) } \\
\text { Tversky and Kahneman (1992) }\end{array}$ \\
\hline 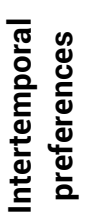 & $\begin{array}{l}\text { PREFERENCE } \\
\text { REVERSALS }\end{array}$ & $\begin{array}{c}\text { Self-control } \\
\text { Hyperbolic discounting }\end{array}$ & $\begin{array}{c}\text { Projection bias } \\
\text { Precommitment } \\
\text { Present bias }\end{array}$ & $\begin{array}{l}\text { Projection bias: Loewenstein et al. (2003) } \\
\text { Self-control: Loewenstein (1996) } \\
\text { Frederick et al. (2002) }\end{array}$ \\
\hline
\end{tabular}

Source: own work 


\subsection{FRAME DEPENDENCE}

The antecedent of frame dependence is the isolation effect (Kahneman and Tversky, 1979): people tend to discard elements shared by all prospects, focusing only on those that distinguish them. This led to the concept of framing (Tversky and Kahneman, 1981): "the decision-maker's conception of the acts, outcomes and contingencies associated with a particular choice" (p. 453), which may produce predictable shifts of preference when the problem is framed differently -a result known as frame dependence. A basic principle is the passive acceptance of the formulation given (Rabin, 1998). Recent articles include laboratory experiments (Dreber et al., 2012; Cason and Plott, 2014; Schlüter and Vollan, 2015) as well as field research (Hossain and List, 2012). In addition, Cornelissen and Werner (2014) reviews framing in the management literature.

Kahneman, Knetsch and Thaler (1986a) allege money illusion is an effect derived from framing. In addition, it influences loss aversion and diminishing sensitivity: a frame that highlights losses makes a choice less attractive, while if it makes losses small, relative to the scales involved, it exploits diminishing sensitivity, making the choice more attractive (Tversky and Kahneman, 1986). Moreover, Kumar and Lim (2008) say framing moderates the disposition effect of active intraday investors because they are more likely to think of portfolio-level outcomes. Finally, related to frame dependence are the concepts of narrow framing, context effects, repeated gambles and hedonic editing.

Narrow framing Narrow framing (Kahneman and Lovallo, 1993) is the tendency to analyze problems in a specific context without reflection of broader considerations (Hirshleifer and Teoh, 2003). Thus, people evaluate risks in isolation, apart from others they already face (Barberis and Huang, 2009). Kahneman (2003a,b) sees it in terms of accessibility: it occurs because decisions are made through intuition instead of effortful reasoning. Some asset pricing models incorporate narrow framing. Thus, Barberis, Huang and Santos (2001) extended asset pricing to a framework where investors derive utility, not only from consumption, but from stock market fluctuations too. Barberis and Huang (2009) improved the model with an intertemporal preference specification that incorporates framing into preferences, and De Giorgi and Legg (2012) extended Barberis and Huang's (2009) model to dynamic portfolio choice and asset pricing. Finally, Barberis, Huang and Thaler (2006) and Barberis and Huang (2007) use a similar model, the former to account for the stock market participation puzzle and the latter to study the equity premium puzzle. 
Context dependence Context effects refer to situations where an individual's preferences among options depend on which other options are in the set (Camerer and Loewenstein, 2004). Thus, adding or subtracting options in a menu of choices may affect the proportion of individuals who choose one of the existing options. Rooderkerk, van Heerde and Bijmolt (2011) review the literature to assert there is robust evidence of three types of context effects: the compromise effect (Simonson, 1989), the attraction effect (Huber, Payne and Puto, 1982), and the similarity effect (Tversky, 1972). Other classics are Simonson and Tversky (1992), who offered examples of context dependence and then, in a subsequent article, provided a model of context-dependent preferences (Tversky and Simonson, 1993). Recent literature provides empirical (Hu and Li, 2011) as well as experimental evidence (Carlsson and Martinsson, 2008) of choice effects in different instances. Finally, Bordalo, Gennaioli and Shleifer $(2012,2013)$ analyze the effects of salience in context-dependent consumer choice and choice under risk.

Repeated gambles Statistical aggregation reduces the relative risk of a series of gambles. Kahneman and Riepe (1998) show that most people do not distinguish between one-time choices and choices where more opportunities to play the same gamble may be available later, setting the same cash-equivalent in both cases. This fails to take advantage of reduced risk in repeated gambles. Benartzi and Thaler (1999) relate this bias to myopic loss aversion. Recent literature includes Liu and Colman (2009), who compare repeated gambles with ambiguity aversion, and Lejarraga and Gonzalez (2011), who find decision makers neglect descriptive information when they can learn from experience.

\subsection{MENTAL ACCOUNTING}

Closely related to framing, mental accounting refers to the implicit methods that individuals use to code and evaluate transactions, investments, gambles, etc. (Kahneman and Tversky, 1984; Thaler, 1985), keeping track of and evaluating their transactions like financial accounting in firms (Thaler, 2008). Shiller (2000a) calls it mental compartments and Statman (1999) puts it shortly: people think "some money is retirement money, some is fun money, some is college education money, and some is vacation money" (p. 19). Thaler (1985) provided a first theory of mental accounting. Later, Thaler (1999) explained people engage in mental accounting activities in three instances: how outcomes are perceived and decisions are made, how activities are assigned to specific accounts -i.e., funds are labeled-, and the frequency with which accounts are evaluated. 
Mental accounting and framing may be used to mitigate self-control problems (Thaler and Shefrin, 1981). Instead, loss aversion causes decision making to be affected by the way alternatives are framed (Tversky and Kahneman, 1986). Following this, Barberis and Huang (2001) observe that the relevant context for loss aversion is gains and losses of each particular investment, rather than gains and losses of total wealth. Finally, Shafir and Thaler (2006) observe some ambiguities may appear when consumption is temporally separated from purchase. Some models make use of the mental accounting principle. Thus, the behavioral portfolio theory (BPT) by Shefrin and Statman (2000) considers investors who segregate their portfolios within multiple mental accounts. Das et al. (2010) integrate some features of BPT and Markowitz's theory into a mental accounting framework to link investor consumption goals and portfolio construction. In turn, Barberis and Shleifer (2003) analyze the tendency to categorize investments into groups, such as growth and value, and observe attitudes toward risk vary across mental accounts. Pan and Statman (2010) obtain empirical evidence of it. Moreover, mental accounting may lead to a house money effect (Hens and Bachmann, 2008). Finally, recent research includes Chen, Kök and Tong (2013), who find experimental evidence of the effects of mental accounting on inventory decisions.

Hedonic editing Related to frame dependence and mental accounting, hedonic editing refers to the evidence that people code combinations of events in a way it make them as happy as possible (Thaler, 1999). Investors, for instance, may choose to interpret problems in a way they seem to be able to avoid a loss (Shefrin, 2000). Alternatively, Thaler and Johnson (1990) suggest a theory of hedonic editing where people organize their mental accounts in a way it makes them feel better. Recent research includes Sul, Kim and Choi (2013), who compare hedonic editing to subjective well-being.

Choice bracketing Decision bracketing is the grouping of individual choices into sets (Read, Loewenstein and Rabin, 1999). Thus, a set of choices are bracketed together when choices are made based on accounting for the effect of each one on all other choices in the set, but not outside it. Narrow bracketing leads to myopic decisions, such as myopic risk seeking (e.g., Haisley, Mostafa and Loewenstein, 2008, offer experimental evidence in the context of lottery play) and myopic loss aversion (e.g., Hardin and Looney, 2012, analyze the variables promoting myopia). Koch and Nafzinger (2016) develop a model of endogenous bracketing, where people set either narrow or broad bracketing to tackle self-control problems. 


\subsection{PROSPECT THEORY}

Prospect theory is the most relevant descriptive theory of decision-making under uncertainty. The literature is so extensive that, for a closest insight, we recommend a recent review by Barberis (2013). In short, according to prospect theory, individuals evaluate the outcomes of risky prospects through a value function, where the carriers of value are changes in wealth compared to a reference point rather than final assets, and a probability weighting function, where probabilities are replaced by decision weights. This allows for the overweighting of tails, a modeling device that captures the common preference for a lottery-like, or positively skewed, wealth distribution (Barberis and Huang, 2008), in accordance with the empirical fact that people tend to put much weight on rare events.

Tversky and Kahneman (1992) developed an extended version, called cumulative prospect theory. It accounts for a distinctive fourfold pattern of risk attitudes confirmed by experimental evidence: people tend to exhibit risk aversion for gains but risk seeking for losses of high probability, and risk seeking for gains but risk aversion for losses of low probability. In addition, the value function being steeper for losses than for gains implies loss aversion. Thus, there are three essential features of the model: reference dependence (the carriers of value are gains and losses defined relative to a reference point), loss aversion (the value function is steeper in the negative than in the positive domain) and diminishing sensitivity (the marginal value of both gains and losses decreases with their size). This results in a value function that is kinked at the reference point, concave above and convex below, and represents investor's loss aversion. Moreover, diminishing sensitivity applies to the weighting function as well. These three features are analyzed in what follows.

\subsubsection{REFERENCE DEPENDENCE}

In prospect theory, it is not final states that carry utility and matters for choice, but changes relative to a reference point. Just how one feels water at $20^{\circ} \mathrm{C}$ fine when weather is cold, and cold when it is hot outside, perception is reference-dependent. A first study of reference points is due to Helson (1964). Later, several candidates to be a natural reference point were proposed. In stock markets, Shefrin and Statman (1985) and Odean (1998a) suggest the privileged role by the buying price. Kõszegi and Rabin (2006) suggest it is set by the subject's rational expectations given the economic environment. Kõszegi and Rabin (2007) describe different options -including the status quo, lagged status quo, and the mean of the chosen lotterythat generate inconsistent predictions on risk attitudes. Koop and Johnson (2012) provide 
experimental evidence of multiple reference points in risky decision-making. Alternatively, Schmidt and Zank (2012) discuss a priori reference dependence in prospect theory, and offer a model on endogenous reference points instead.

Another implication of prospect theory in a dynamic context is that reference points may change over time, following gains and losses. Arkes et al. (2008) find an asymmetry: the magnitude of the adaptation is significantly greater following a gain than after a loss of equivalent size. The asymmetric adaptation suggests hedonic editing, as it results from the benefits of segregating intertemporal gains and integrating intertemporal losses (Thaler, 1999). Baucells, Weber and Welfens (2011) find reference points are not recursive, in the sense that the new one is not a combination of the previous one and the new information, but a combination of the purchase (first) and the current (last) price of the time series. Arkes et al. (2010) analyze how cultural differences influence reference point adaptation (see Section 5). Finally, reference points are closely related to diminishing sensitivity and loss aversion, as well as to the status quo bias (Tversky and Kahneman, 1991), among others.

Anchoring-and-adjustment A key judgmental bias in risk perception, the literature starts with Tversky and Kahneman (1974), who describe it as "people make estimates by starting from an initial value that is adjusted to yield the final answer" (p. 1128), an adjustment that is often insufficient. The reference point may be given by the formulation of the problem, as in their classic wheel-of-fortune experiment. Epley and Gilovich (2010) consider this first wave of research over, as subsequent articles provided little or no support to the hypothesis. However, Epley and Gilovich (2001) found that insufficient adjustment produces anchoring effects when anchors are selfgenerated, and Epley and Gilovich (2006) offered evidence. Thus, a second wave of research tried to set the psychological mechanisms that produce anchoring effects. These include a confirmatory hypothesis testing (Chapman and Johnson, 1994), numeric or magnitude priming (Oppenheimer, Leboeuf, and Brewer, 2008), and insufficient adjustment (Tversky and Kahneman, 1974; Epley and Gilovich, 2001). Frederick, Kahneman and Mochon (2010) elaborate a theory of anchoring. Finally, a third wave makes predictions about the consequences of anchoring. Furnham and Boo (2011) provide a recent literature review. The most relevant are perhaps underreaction (Barberis and Thaler, 2003) and biases such as conservatism (Shefrin, 2000). 
Conservatism Defined as the slow updating of models in face of new evidence (Shleifer, 2000), conservatism explains why markets often respond gradually to new information (Chan, Jegadeesh and Lakonishok, 1996). It results in earnings reflecting bad news more quickly than good news (Basu, 1997). Thus, conservatism would explain the profitability of momentum strategies (Chan et al., 1996) and the evidence of underreaction (Barberis et al., 1998). Early papers include Edwards (1968), and analysis on multistage evaluation (e.g., Gettys, Kelly and Peterson, 1973). Recent literature relates return predictability in stock markets to Generally Accepted Accounting Principles (GAAP) such as the conservatism principle (Ball, Kothari and Nikolaev, 2013; Zhang, 2013).

\subsubsection{LOSS AVERSION}

In prospect theory, subjects assign more significance to losses than to gains with respect to the reference point. This asymmetry in the value function is called loss aversion (Kahneman and Tversky, 1984): people suffer a loss more acutely than they enjoy a gain of the same magnitude (Shefrin, 2006), with the evidence of negativity biases in non-monetary domains reinforcing this belief (McGraw et al., 2010). However, this represents a contradiction to rational choice: Knetsch (1989) shows that if loss aversion exists, the basic property of expected utility theory, that two indifference curves never intersect, no longer holds. The influence of loss aversion in choices is observed in different contexts (e.g., Thaler, 1985; Kahneman, Knetsch and Thaler, 1990; Camerer, 2000; Novemsky and Kahneman, 2005). It may explain empirical findings like the disposition effect and higher levels of trade when prices are rising (Shefrin and Statman, 1985), how the number of market transactions may be reduced (Knetsch, 1989), and why consumers and managers may take fewer risks (Rabin, 2000). It is also related to the endowment effect and the status quo bias. Tversky and Kahneman (1991) offer a theory of consumer choice based on loss aversion, and provide empirical evidence that losses are weighted about twice as gains.

Cesarini et al (2012) show loss aversion is moderately heritable. In addition, loss salience extends the notion to the social sphere: we care more about the financial losses of others than their gains (Hirshleifer, 2008). However, researchers have identified some limits of loss aversion, too. Novemsky and Kahneman (2005) obtain experimental evidence that those exchanging goods, given up as intended (e.g., money paid in purchases), do not exhibit loss aversion. McGraw et al. (2010) note that the empirical evidence of loss aversion on feelings is mixed, because while choice enforces comparison, judging feelings does not necessarily require it -instead, we tend to 
compare similar outcomes (i.e., losses against losses). Finally, Polman (2012) shows loss aversion is lessened when we choose for others.

Myopic loss aversion The combination of loss aversion and the investors' common habit of evaluating their portfolios is frequently known as myopic loss aversion (Benartzi and Thaler, 1995). Gneezy, Kapteyn and Potters (2003) provided experimental evidence. Thaler et al. (1997) provided empirical evidence that investors will be more willing to accept risks if they evaluate investments less often, and if all payoffs are incremented enough as to eliminate losses. Langer and Weber (2005) extend the concept to myopic prospect theory: when myopic loss aversion combines with diminishing sensitivity and probability weighting, the effect of myopia might increase the willingness to invest. Fellner and Sutter (2009) discuss some debiasing techniques.

\subsubsection{DIMINISHING SENSITIVITY}

Marginal effects in perceived well-being are greater for changes close to the refence level than for changes further away (Rabin 1998). This third essential feature of prospect theory applies to both the value and weighting functions. In regards to the value function, Kahneman and Tversky (1979), noting diminishing sensitivity is a pervasive pattern of human perception, conjectured it would be concave for gains and convex for losses. This in turn implies people are likely to be risk averse over gains, but willing to gamble in the negative domain to avoid losses. In regards to the weighting function, Tversky and Kahneman (1992) note: "In the evaluation of uncertainty, there are two natural boundaries - certainty and impossibility - that correspond to the endpoints of the certainty scale. Diminishing sensitivity entails that the impact of a given change in probability diminishes with its distance from the boundary" (p. 303). In consequence, risk-seeking choices are commonly observed in two instances: the aversion to a sure loss and the favorite-longshot bias. The former stems directly from the shape of the value function; the latter represents instead a miscalibration of probabilities that is often related to the weighting function.

Aversion to a sure loss Prospect theory asserts most people are risk averse, as standard finance predicts, but only when confronted with the expectation of a financial gain. Instead, when facing the possibility of losing money, people often behave as risk lovers, choosing to accept an actuarially unfair risk in an attempt to avoid a sure loss (Shefrin, 2006). Adam and Kroll (2012) suggest decision makers perceive lotteries as dynamic processes where emotions may lead to 
attraction to chance. Schwager and Rothermund (2013) provide evidence on the effects of framing and attention bias.

Favorite-longshot bias In betting markets it is often observed that bettors put too much weight on rare events (longshot bets) while they underestimate the probability of favorites. Thus, the expected return on longshot bets tends to be systematically lower than on favorite bets (Ottaviani and Sorensen, 2007), or alternatively, the normalized prices on the favorites understate their winning chances while exaggerating those on the longshots (Shin, 1992). The favorite-longshot bias is one of the most studied biases in behavioral finance. The first documentation is attributed to Griffith's (1949) observation of this behavior in horse-race betting. Recent studies include Hodges, Tompkins and Ziemba (2008) in the derivatives markets, Page and Clemen (2013) in prediction markets, and Lahvicka (2014) in sports. Some possible explanations are misestimation of probabilities (Griffith, 1949), market power of informed bettors and uninformed bookmakers, preference for risk, heterogeneous beliefs (Shin, 1992), limited arbitrage by informed bettors, and simultaneous betting by partially informed insiders (Ottaviani and Sorensen, 2007).

\subsection{PREFERENCE REVERSALS}

Intertemporal preferences are rational if they are time consistent, i.e., if people exhibit no preference reversals when making decisions over time (Hens and Bachmann, 2008). However, empirical evidence shows people do exhibit reversals, have problems with committing to decisions they took in the past, and exhibit present-biased preferences. For simplicity, we see these concepts together under the epigraph of preference reversals, which include problems of self-control and a present bias in intertemporal decision-making.

Hyperbolic discounting or present bias Standard economic models compare preferences over time with exponential discounting, implying time consistency and a 100\% short-term patience. However, there is much evidence that people exhibit present-biased preferences instead. This accounts for different immediate and future discounting: one can be extremely patient in the long run and very impatient in the short run, a bias known as immediacy effect. In the words of Rabin (2002a, p. 668): “We are more averse to delaying today's gratification until tomorrow than we are averse to delaying the same gratification from 90 days to 91 days from now." 
An antecedent to the study of changes in preferences were Phelps and Pollak (1968), who reviewed Ramsey's postulate of a perfect altruism along generations. Subsequent empirical research showed preferences typically reverse with changes in delay, as predicted by hyperbolic discounting (Kirby and Herrnstein, 1995). A classic early review by Frederick, Loewenstein and O'Donoghe (2002) observes much cross-study differences in discount rates, against the assumption of a single rate under exponential discounting. However, the debate continues today. Andersen et al. (2008) showed that, in order to provide credible estimates, a joint estimation of risk and time preferences should be performed. Andreoni and Sprenger (2012) provided similar results. Thus, the discounting anomalies previously observed in the literature had to be re-tested. Andersen et al. (2014) provide a detailed review of the comparable literature, and experimental results with no evidence favorable to hyperbolic discounting. Finally, some models follow. Scholten and Read (2006) suggest discount rates depend on the length of the intervals between outcomes. Bordalo et al. (2012) and Tsetsos, Chater and Usher (2012) model preference reversals as a consequence of the salience of the different payoffs. Finally, Stevens (2016) suggests people do not discount, rather they compare within attributes (amounts and delays) to determine if differences in one attribute outweigh differences in another attribute.

Self-control (and precommitment) Related to preference reversals is the existence of a projection bias: people exaggerate the degree to which their future tastes will be similar to their current ones. Loewenstein, O'Donoghue and Rabin (2003) provide evidence and model this bias, which makes people consume too much early in life, and to consume more and save less than originally planned as time passes. Recent research includes Zeisberger, Vrecko and Langer (2015) on the stability of prospect theory parameters.

Being aware in advance that our preferences may change, we sometimes make certain decisions to restrict our own future flexibility (Rabin, 1998). Strotz (1955) noted we may choose to precommit our future behavior by excluding future options. He named those who are aware of future self-control problems as sophisticated, and those who are not, naïve. Loewenstein (1996) concludes, however, that any of us may end up being naïve due to psychological biases that make us mispredict changes in utility. Experimental research on self-control includes Burger, Charness and Lynham (2011). Thaler and Shefrin (1981) suggest mental accounting and framing may be used to mitigate self-control problems. Shefrin (2000) relates self-control to preference for dividends: 
some investors may prefer dividends because they don't want to dip into capital. Gatherwood and Weber (2014) provide a similar interpretation to why some people co-hold high-cost consumer credit and low yield liquid savings.

\section{SOCIAL FACTORS}

The last category ensembles some items that refer to the impact of cultural and social factors on an individual's behavior. This is the least developed body of literature in behavioral economics and finance, but in Hirshleifer (2015)'s words, "the time has come to move beyond behavioral finance to social finance, which studies the structure of social interactions, how financial ideas spread and evolve, and how social processes affect financial outcomes." (p.133). The social factors are shown in Table 3 and reviewed below.

TABLE 3. Social factors

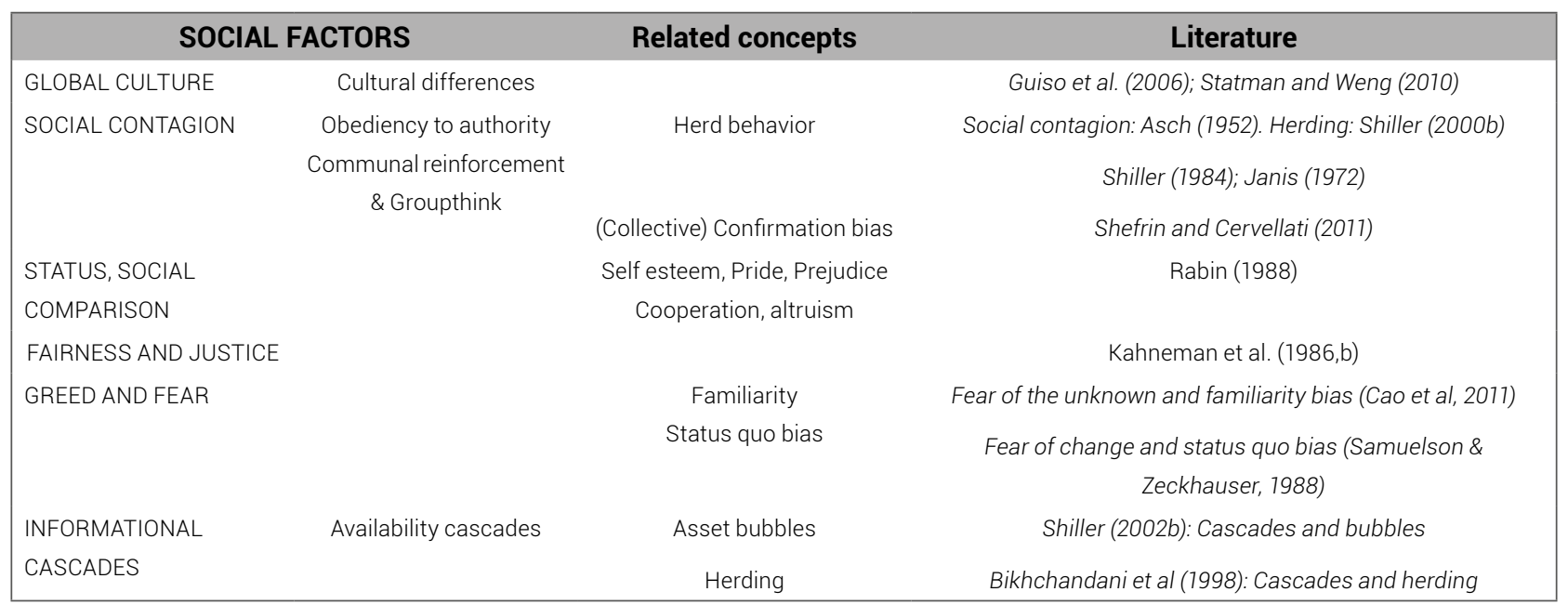

Source: own work

\subsection{GLOBAL CULTURE}

Culture is the values that ethnic, religious, and social groups transmit across generations (Statman and Weng, 2010). The first to cite culture as a determinant of economic growth was perhaps Weber (1905), who argued the Protestant Reformation was crucial to the development of capitalism. Cultural psychology has a significant influence on social psychology as well (e.g. Miller, 1984). However, economists were reluctant to use culture as an explanatory factor because of the vague and ubiquitous ways it can enter the economic discourse, making it difficult to design testable 
hypotheses (Guiso, Sapienza and Zingales, 2006). Recent techniques and data have made it possible to identify systematic differences in people's beliefs, and relate them to their cultural legacy. Some examples follow.

Shiller (2000a) notices the emergence of a global culture in examples of imitation or convergence of fashions across countries separated by physical and language barriers. Shiller (2000b) suggests cultural factors help explain the dot-com bubble, such as the belief we were entering a new era. Stulz and Williamson (2003) claim culture may affect finance through the country's values, institutions, and how resources are allocated. Indeed, Levinson and Peng (2007) observe that the way people perceive events is influenced by culture. Some authors analyze how it affects expectations and preferences. These include Guiso et al. (2006) on culture and prior beliefs in decision making, Henrich et al. (2001) on variations across tribes in the ultimatum and dictator games, and Hoff and Priyanka (2004) who show the effects of social inequality linger: beliefs that are the legacy of extreme inequality for generations determine an individual's expectations that reproduce the inequality.

Cultural differences Though a global culture might be emerging, cultural differences are ubiquitous. Nisbett and Masuda (2003) describe how East Asians and Westerners perceive the world and think of it differently. Thus, East Asians exhibit a broader perceptual and conceptual view of the world, live in complex social networks, and notice relationships and changes, contrary to Westerners. Arkes et al. (2010) study cultural differences between China, Korea and the U.S., in reference point adaptation following gains or losses in security trading. Differences between Asians and Americans are also studied by Ji et al. (2001), who show Chinese anticipate more changes and their direction; and Levinson and Peng (2007) and Chen et al. (2007), who observe differences in framing, morality, overconfidence and disposition effect. Finally, studies on cultural differences in economic and financial variables include Statman and Weng (2010), who find different borrowing and investing patterns of immigrants long after they settled in their new countries, and Beugelsdijk and Frijns (2010), who show that the degree of cultural distance between two countries affects foreign asset allocations. Recent literature analyzes the effects on corporate structure (Bloom, Sadun and van Reenen, 2015), financial contracts (Gianneti and Yafeh, 2012), innovation rates (Taylor and Wilson, 2012), and corporate M\&As (Ahern, Daminelli and Fracassi, 2015). 


\subsection{SOCIAL CONTAGION}

A key distinction between social interaction and culture is that the former focuses on peer group effects that can be viewed as the fast-moving component of culture (Guiso et al., 2006), whereas culture topics rely on inherited, slow-moving components. The antecedents in the study of social contagion are Sherif (1937), in his experiment on the autokinetic effect, and the classic Asch's experiment (Asch, 1952): subjects tend to answer the same obviously wrong answers as other people participating in the experiment, confederated with Asch, highlighting the power of social pressure on individual judgment. Manski (2000) surveys the literature and suggests that the neoclassical view, where non-market interactions are not of interest, ended by the 1970s with the adoption of non-cooperative dynamic game theory. Recent contributions include empirical evidence by Rapp et al. (2013), experimental research by Aral and Walker (2014) on viral marketing, and models such as Pacheco (2012) on how public opinion influences policy diffusion.

Obedience to authority Milgram's experiments (Milgram, 1963, 1974) showed few people has the initiative to resist authority, to the point of performing acts that violate their deepest moral beliefs. Most subjects were willing to hurt or even kill another person if they were simply asked to do it, with no coercive methods, by a person or institution they recognized as an authority. Years before, Festinger (1957) analyzed the effects of forced compliance, showing that a person forced to do something contrary to her opinion may eventually change her view in order to avoid cognitive dissonance. Shiller (2000b) links herd behavior to social contagion and obedience to authority, suggesting that the study of asset bubbles could draw upon epidemic models used by sociologists to predict the course of word-of-mouth transmission of ideas. An alternative approach, obedience to legitimate authority, may be positive, encouraging individuals to set aside their selfish desires for the good of their group (Ent and Baumeister, 2014).

Communal reinforcement and groupthink Communal reinforcement is a type of social dynamic. An early article on social psychology of individual suggestibility, group pressure and diffusion of opinions is Katona (1901), who used the term social learning for the process of "mutual reinforcement through exchange of information among peer groups by word of mouth" (p. 203). Shiller (1984) states that examples of social dynamics are investors who follow gurus, read magazines, discuss investments with other investors... and through this process, market psychology influences markets. Groupthink, a term coined by Janis (1972), is the tendency of cohesive groups to reach consensus 
without offering, seeking or considering alternative hypothesis (Lunenburg, 2010). Janis (1972) identifies some symptoms of groupthink, including an illusion of invulnerability that leads groups to take excessive risks, or members imposing themselves a self-censorship to avoid appearing as a dissenter. Shefrin and Cervellati (2011) interpret it as a form of collective confirmation bias. Recent literature includes Mayo-Wilson, Zollman and Danks (2012) on individual and group rationality, and Nofsinger (2012), who offers a model of asset bubbles fueled by groupthink.

\subsection{STATUS, ENVY AND SOCIAL COMPARISON}

A field of social psychology relevant to economics is the self-perception compared to others, and the feelings of jealousy, self-esteem, pride and prejudice such comparison provokes. We denote this category 'status, envy and social comparisons' as in Rabin (1998). Not all feelings stemming from social comparisons are negative, as cooperation (Argyle, 1991) or reciprocal altruism (Trivers, 1971) fall within this category.

Some examples of this literature follow in order. Salovey and Rodin (1984) analyze the effects of jealousy. In regards to altruism, Carpenter and Myers (2010) examine the motivations for prosocial behavior, and Ariely, Bracha and Meier (2009) show that extrinsic incentives can reduce charitable donations and volunteering as they dilute the signaling value of prosocial behavior. Gilbert, Price and Allan (1995) suggest social comparison occurs in many forms of human interaction, including relative social hierarchy (status) and reciprocity (altruism). Richins (1991) reviews the literature on consumer dissatisfaction when they compare themselves with the idealized advertising images. Ball and Eckel (1998) study how social status influences economic behavior. Ball et al. (2001) test the effects of social status in an experimental market. Heffetz and Frank (2011) review the literature on preferences for social status.

\subsection{FAIRNESS AND JUSTICE}

According to Kahneman, Knetsch and Thaler (1986b), "the absence of considerations of fairness and loyalty from standard economic theory is one of the most striking contrasts between this body of theory and other social sciences" (p. S285). Akerlof (1979) and Solow (1980) use fairness to explain why firms often do not cut wages during periods of high unemployment, giving rise to the literature of efficiency wages. Okun (1981) says fairness can also alter the outcomes in customer markets -where suppliers have some monopoly power 
and repeat business with their clientele. Camerer and Loewenstein (2004) observe people spend money to punish others who have harmed them, to reward those who have helped, or to make outcomes fairer. Güth, Schmittberger and Schwarze (1982) conduct a series of dictator and ultimatum games to show people often rely on what they consider a fair or justified result. Further analyses of these games are available in Camerer and Thaler (1995) -on ultimatum games- and List (2007) -on dictator games.

Fairness and justice are related to behavioral effects like money illusion: people observe nominal rather than real changes in wages and prices to assess the fairness of a firm's behavior (Kahneman et al., 1986a). The endowment effect implies people feel foregone gains (opportunity costs) less painfully than perceived losses (out-of-pocket costs). Hence, our perceptions strongly depend on whether a question is framed as a gain reduction or an actual loss (Kahneman et al., 1991). Thaler (1985) and Kahneman et al. (1986a,b) find fairness is relevant for customers to determine their reference prices, with loss aversion playing a key role in what they find to be acceptable. Finally, Shleifer (2004) observes ethics and efficiency go together when ethical norms promote cooperative behavior, helping for the successful functioning of social institutions. Additional literature includes Bolton and Ockenfels (2000) on equity and competition, Falk, Fehr and Fischbacher (2003) and Nguyen and Klaus (2013) on perceptions of fairness, Liu et al. (2014) on four types of justice in the buyer-supplier relationship, Sen (1995) on moral values, and Durante, Putterman and van der Weele (2014) on inequality and preferences for redistribution.

\subsection{GREED AND FEAR}

Both being emotional factors, greed and fear could certainly be associated to the affect heuristic in Section 3. However, we opt to classify them as social factors because these biases tend to appear when individuals interact with each other, particularly in financial markets where fear, greed, and other emotional responses are a common argument against the efficient market hypothesis. Shefrin (2000)'s "Beyond Greed and Fear" identifies human emotions as determinants of risk tolerance and portfolio choice. Lo, Repin and Steenbarger (2005) offer experimental evidence of a negative correlation between successful trading and emotional reactivity. Pan and Statman (2010) show risk tolerance varies with test conditions and the emotions associated to them. 
Fear is related to other biases. Fear of the unknown would be an explanation for the familiarity heuristic (Cao et al., 2011). Fear of change, a possible explanation for the status quo bias (Samuelson and Zeckhauser, 1988). Moreover, fear and greed would play a key role in concepts like market sentiment, bubbles and crashes, social contagion, and others (Shiller, 2000a; Shefrin, 2000). However, Shleifer (2004) claims that the unethical behavior blamed to stem from greed is often a consequence of market competition. Recent research includes Lee and Andrade (2011), who show social projection explains why fear leads to early sell-off in a stock market simulation.

\subsection{INFORMATIONAL CASCADES}

News media often act as precipitators of attention cascades: significant market events only occur if large groups of people think the same, and news media could be the vehicles for such spread of ideas. For example, Shiller (2000b) cites informational cascades among the causes of the dotcom bubble. Bikhchandani, Hirshleifer and Welch (1998) argue that some puzzling phenomena such as herding, fads, asset bubbles and crashes may be seen as consequences of informational cascades. We learn by observing what others do, and then we imitate them. Imitation would be an evolutionary adaptation for survival, allowing individuals to take advantage of the hard-won information of others. Wu (2015) extends Bikhchandani et al (1998)'s model. Other models include Hansen, Hendricks and Rendsvig (2013), and Rubin (2014).

Availability cascades Related to informational cascades, these are self-reinforcing processes of collective belief formation that have a combination of informational and reputational motives as driving factors (Kuran and Sunstein, 1999). By the availability heuristic, people judge the importance of a theme according to their ability to remember examples of it. Then, as a chain reaction result, the more people talk about an issue the more relevant it seems due to its rising availability in public discourse, leading to a self-reinforcing cycle (Hirshleifer, 2008).

\section{CONCLUDING REMARKS}

We have provided a comprehensive review of the main behavioral biases that lead to market anomalies and decision effects that contradict the basic tenets of standard economics and finance. The literature is very vast and diverse. However, from the analysis made, we obtain a set of conclusions. 
First, we defined three broad categories of behavioral biases: heuristics and biases, choices (framing and preferences), and social factors. Among them, representativeness, overconfidence, prospect theory and social contagion are perhaps the most recurrent. The second result is that, within each category, we offered a list of relevant biases, and an updated revision of the most relevant articles, theoretical and empirical, that have covered them. Finally, we disclose these biases together with other biases and anomalies related to them, according to the literature.

Further reviews from here might focus on the main decision effects and market anomalies that stem from these biases, as well as on providing further insight on recent advances in the psychological biases and anomalies research program.

\section{REFERENCES}

Ackert, L., Church, B., Tompkins, J. y Zhang, P. (2005). What's in a name? An experimental examination of investment behavior. Review of Finance 9, 281-304.

Adam, M. y Kroll, E. (2012). Physiological evidence of attraction to chance. Journal of Neuroscience, Psychology and Economics 5(3), 152-165.

Ahern, K., Daminelli, D. y Fracassi, C. (2015). Lost in translation? The effect of cultural values on mergers around the world. Journal of Financial Economics 117(1), 165-189.

Akerlof, G. (1979). The case against conservative macroeconomics: An inaugural lecture. Economica, $46,219-237$.

Akerlof, G. y Shiller, R. (2009). How animal spirits destabilize economies. McKinsey Quarterly 3, 127-135.

Alary, D., Gollier, C. y Treich, N. (2013). The effect of ambiguity aversion on insurance and self-protection. The Economic Journal, 123, 1188-1202.

Alós-Ferrer, C. y Hügelschäfer, S. (2012). Faith in intuition and behavioral biases. Journal of Economic Behavior \& Organization, 84, 182-192. 
Alpert, M. y Raifa, H. (1969). A progress report on the training of probability assessors. Kahneman, D., Slovic, P. y Tversky, A. (Edts.). Judgment under uncertainty: Heuristics and biases. Cambridge University Press.

Andersen, S., Harrison, G., Lau, M. y Rutström, E. (2008). Eliciting risk and time preferences. Econometrica, 76(3), 583-618.

Andersen, S., Harrison, G., Lau, M. y Rutström, E. (2014). Discounting behavior: A reconsideration, European Economic Review, 71, 15-33.

Andreoni, J. y Sprenger, C. (2012). Risk preferences are not time preferences. American Economic Review, 102(7), 3357-76.

Aral, S. y Walker, D. (2014). Tie strength, embeddedness, and social influence: A large-scale networked experiment. Management Science 60(6), 1352-70.

Argyle, M. (1991). Cooperation: The basis of sociability. Routledge.

Ariely, D., Bracha, A. y Meier, S. (2009). Doing good or doing well? Image motivation and monetary incentives in behaving prosocially. The American Economic Review, 99(1), 544-555.

Arkes, H., Hirshleifer, D., Jiang, D. y Lim, S. (2008). Reference point adaptation: Tests in the domain of security trading. Organizational Behavior and Human Decision Processes, 105, 67-81.

Arkes, H., Hirshleifer, D., Jiang, D. y Lim, S. (2010). A cross-cultural study of reference point adaptation: Evidence from China, Korea and the US. Organizational Behavior and Human Decision Processes, 112(2), 99-111.

Asch, S. (1952). Social Psychology. Prentice Hall.

Baker, M., Ruback, R. y Wurgler, J. (2007). Behavioral corporate finance: A survey. Eckbo, E. (edit.). The handbook of corporate finance: empirical corporate finance. Elsevier. 
Ball, R., Kothari, S. y Nikolaev, V. (2013). Econometrics of the Basu asymmetric timeliness coefficient and accounting conservatism. Journal of Accounting Research, 51(5), 1071-97.

Ball, S. y Eckel, C. (1998). The economic value of status. Journal of Socio-Economics, 27(4), 495-514.

Ball, S., Eckel, C., Grossman, P. y Zane, W. (2001). Status in markets. The Quarterly Journal of Economics, 116(1), 161-188.

Barber, B. y Odean, T. (2001). Boys will be boys: Gender, overconfidence, and common stock investment, The Quarterly Journal of Economics, 116(1), 261-292.

Barber, B. y Odean, T. (2008). All that glitters: The effect of attention and news on the buying behavior of individual and institutional investors. Review of Financial Studies, 21(2), 785-818.

Barberis, N. (2013). Thirty years of prospect theory in Economics: A review and assessment. The Journal of Economic Perspectives, 27(1), 173-195.

Barberis, N. y Huang, M. (2001), Mental accounting, loss aversion and individual stock returns, The Journal of Finance 56(4), 1247-92.

Barberis, N., Huang, M. y Santos, T. (2001). Prospect theory and asset prices. The Quarterly Journal of Economics, 116(1), 1-53.

Barberis, N., Huang, M. y Thaler, R. (2006). Individual preferences, monetary gambles, and stock market participation: A case for narrow framing. American Economic Review, 96, 1069-1090.

Barberis, N. y Huang, M. (2007). The loss aversion/narrow framing approach to the equity premium puzzle. Mehra, R. (edit.) Handbook of Investments: Equity Premium, (pp. 199-229).

Barberis, N. y Huang, M. (2008). Stock as lotteries: The implication of probability weighting for security prices. American Economic Review, 98(5), 2066-2100. 
Barberis, N. y Huang, M. (2009). Preferences with frames: A new utility specification that allows for the framing of risks. Journal of Economics Dynamics \& Control, 33(8), 1555-76.

Barberis, N., Shleifer, A. y Vishny, R. (1998). A model of investor sentiment. Journal of Financial Economics, 49(3), 307-343.

Barberis, N. y Shleifer, A. (2003). Style investing. Journal of Financial Economics, 68, 161-199.

Barberis, N. y Thaler, R. (2003). A survey of Behavioral Finance. Constantinides, G., Harris, M. y Stulz, R. (edits.). Handbook of the Economics of Finance, 1(1), 1053-1128.

Bar-Hillel, M. (1973). On the subjective probability of compound events. Organizational Behavior \& Human Performance, 9, 396-406.

Basu, S. (1997). The conservatism principle and the asymmetric timeliness of earnings. Journal of Accounting and Economics, 24(1), 3-37.

Battalio, R., Lerman, A., Livnat, J. y Mendenhall, R. (2012). Who, if anyone, reacts to accrual information? Journal of Accounting and Economics, 53, 205-224.

Baucells, M., Weber, M. y Welfens, F. (2011). Reference point formation and updating: Theory and experiments. Journal Management Science, 57(3), 506-519.

Belsky, G. y Gilovich, T. (1999). Why smart people make big money mistakes and how to correct them: Lessons from the new science of behavioral economics. Simon \& Schuster.

Bem, D. (1965). An experimental analysis of self-persuasion. Journal of Experimental Social Psychology, 1(3), 199-218.

Benartzi, S. (2001). Excessive extrapolation and the allocation of $401(\mathrm{k})$ accounts to company stock? American Economic Review, 91(1), 79-98. 
Benartzi, S. y Thaler, R. (1995). Myopic loss aversion and the equity premium puzzle. The Quarterly Journal of Economics, 110(1), 73-92.

Benartzi, S. y Thaler, R. (1999). Risk aversion or myopia? Choices in repeated gambles and retirement investments. Management Science 45(3), 364-381.

Beugelsdijk, S. y Frijns, B. (2010). A cultural explanation of the foreign bias in international asset allocation. Journal of Banking and Finance, 34, 2121-31.

Biais, B., Hilton, D., Mazurier, K. y Pouget, S. (2005). Judgmental overconfidence, self-monitoring and trading performance in an experimental financial market. Review of Economic Studies, 72(2), 287-312.

Bikhchandani, S., Hirshleifer, D. y Welch, I. (1998). Learning from the behavior of others: Conformity, fads, and informational cascades. The Journal of Economic Perspectives, 12(3), 151-170.

Bloom, N., Sadun, R. y van Reenen, J. (2015). The organization of firms across countries. Quarterly Journal of Economics, 127(4), 1663-1705.

Bolton, G. y Ockenfels, A. (2000). ERC: A theory of equity, reciprocity, and competition. American Economic Review, 90(1), 166-193.

Bordalo, P., Gennaioli, N. y Shleifer, A. (2012). Salience theory of choice under risk. The Quarterly Journal of Economics, 127(3), 1243-85.

Bordalo, P., Gennaioli, N. y Shleifer, A. (2013). Salience and consumer choice. Journal of Political Economy, 121(5), 803-843.

Boyle, P., Garlappi, L., Uppal, R. y Wang, T. (2012). Keynes meets Markowitz: The trade-off between familiarity and diversification. Management Science, 58(2), 253-272.

Bracha, A. y Brown, D. (2012). Affective decision making: A theory of optimism bias. Games and Economic Behavior, 75(1), 67-80. 
Briley, D., Shrum, L. y Wyer, R. (2013). Factors affecting judgments of prevalence and representation: Implications for public policy and marketing. Journal of Public Policy \& Marketing, 32, 112-118.

Burger, N., Charness, G. y Lynham, J. (2011). Field and online experiments on self-control. Journal of Economic Behavior \& Organization, 77(3), 393-404.

Burnside, C., Han, B., Hirshleifer, D. y Wang, T. (2011). Investor overconfidence and the forward premium puzzle. Review of Economic Studies, 78(2), 523-558.

Camerer, C. (2000). Prospect theory in the wild: Evidence from the field. Kahneman y Tversky, A. (edits.). Choices, Values, and Frames, (pp. 288-300). Cambridge University Press.

Camerer, C. y Lovallo, D. (1999). Overconfidence and excess entry: An experimental approach. The American Economic Review, 89(1), 306-318.

Camerer, C. y Loewenstein, G. (2004). Behavioral economics: past, present, future. Camerer, G., Loewenstein y Rabin, M. (edits.). Advances in Behavioral Economics, (pp. 3-51). Princeton University Press.

Camerer, C. y Thaler, R. (1995). Anomalies: ultimatums, dictators and manners. Journal of Economic Perspectives, 9(2), 209-219.

Cao, H., Han, B., Hirshleifer, D. y Zhang, H. (2011). Fear of the unknown: familiarity and economic decisions. Review of Finance, 15(19), 173-206.

Carlsson, F. y Martinsson, P. (2008). How much is too much? An investigation of the effect of the number of choice sets, context dependence and the choice of bid vectors in choice experiments. Environmental and Resource Economics, 40, 165-176.

Carpenter, J. y Myers, C. (2010). Why volunteer? Evidence on the role of altruism, image, and incentives. Journal of Public Economics, 94, 911-920. 
Cason, T. y Plott, C. (2014). Misconceptions and game form recognition: Challenges to theories of revealed preference and framing. Journal of Political Economy, 122(6), 1235-70.

Cesarini, D., Johannesson, M., Magnusson, P. y Wallace, B. (2012). The behavioral genetics of behavioral anomalies. Management Science, 58(1), 21-34.

Chan, L., Jegadeesh, N. y Lakonishok, J. (1996). Momentum strategies. The Journal of Finance, 51(5), 1681-1713.

Chapman, G. y Johnson, E. (1994). The limits of anchoring. Journal of Behavioral Decision Making, 7, 223-242.

Chelley-Steeley, P., Kluger, B. y Steeley, J. (2015). Earnings and hindsight bias: An experimental study. Economic Letters, 134, 130-132.

Chen, G., Kim, K., Nofsinger, J. y Rui, O. (2007). Trading performance, disposition effect, overconfidence, representativeness bias, and experience of emerging market investors. Journal of Behavioral Decision Making, 20(4), 425-451.

Chen, L., Kök, A. y Tong, J. (2013). The effect of payment schemes on inventory decisions: The role of mental accounting. Management Science, 59(2), 436-451.

Chew, S., Ebstein, R. y Zhong, S. (2012). Ambiguity aversion and familiarity bias: Evidence from behavioral and gene association studies. Journal of Risk and Uncertainty, 44(1), 1-18.

Chou, H. y Edge, N. (2012). "They are happier and having better lives than I am": The impact of using Facebook on perceptions of others' lives. Cyberpsychology, behavior and social networking, 15(2), 117-121.

Cokely, E. y Kelley, C. (2009). Cognitive abilities and superior decision making under risk: A protocol analysis and process model evaluation. Judgmental Decision Making, 4(1), 20-33. 
Cornelissen, J. y Werner, M. (2014). Putting framing in perspective: A review of framing and frame analysis across the management and organizational literature. The Academy of Management Annals, 8(1), 181-235.

Cosmides, L. y Tooby, J. (1990). Is the mind a frequentist? Second Annual Meeting of the Human Behavior and Evolution Society, LA, CA. Cited in G. Gigerenzer (1991), How to make cognitive illusions disappear: Beyond 'heuristics and biases'. Stroebe y Hewstone, M. (edits.). European Review of Social Psychology, Wiley.

Cowen, A., Groysberg, B. y Healy, P. (2006). Which types of analyst firms are more optimistic? Journal of Accounting and Economics, 41(1-2), 119-146.

Cowley, E., Briley, D. y Farrell, C. (2015). How do gamblers maintain an illusion of control? Journal of Business Research, 68(10), 2181-88.

Daniel, K., Hirshleifer, D. y Subrahmanyam, A. (1998). Investor psychology and security market under- and overreactions. The Journal of Finance, 53(6), 1839-85.

Das, S., Markowitz, H., Scheid, J. y Statman, M. (2010). Portfolio optimization with mental accounts. Journal of Financial and Quantitative Analysis, 45(2), 311-334.

De Giorgi, E. y Legg, S. (2012). Dynamic portfolio choice and asset pricing with narrow framing and probability weighting. Journal of Economic Dynamics \& Control, 36(7), 951-972.

DellaVigna, S. (2009). Psychology and Economics: Evidence from the field. Journal of Economic Literature, 47(2), 315-372.

Dreber, A., Ellingsen, T., Johannesson, M. y Rand, D. (2012). Do people care about social context? Framing effects in dictator games. Experimental Economics, 16(3), 349-371.

Du, N. y Shelley, M. (2014). Exploring ambiguity and familiarity effects in the "earnings game" between managers and investors. Journal of Behavioral Finance, 15(1), 70-77. 
Duong, C., Pescetto, G. y Santamaria, D. (2014). How value-glamour investors use financial information: UK evidence of investors' confirmation bias. The European Journal of Finance, 20(6), 524-549.

Durante, R., Putterman, L. y van der Weele, J. (2014). Preferences for redistribution and perception of fairness: An experimental study. Journal of the European Economic Association, 12(4), 1059-1086.

Edwards, W. (1968). Conservatism in human information processing. Reprinted short version in Kahneman, D. Slovic, P. y Tversky, A. (1982), Judgment under uncertainty: Heuristics and biases. Cambridge University Press.

Einhorn, H. y Hogarth, R. (1978). Confidence in judgment: Persistence of the illusion of validity. Psychological Review, 85(5), 395-416.

Einhorn, H. y Hogarth, R. (1986). Decision making under ambiguity. Journal of Business, 59(4), S225-S250.

Ent, M. y Baumeister, R. (2014). Obedience, self-control, and the voice of culture. Journal of Social Issues, 70(3), 574-586.

Epley, N. y Gilovich, T. (2001). Putting adjustment back in the anchoring and adjustment heuristic: Differential processing of self-generated and experimenter-provided anchors. Psychological Science, 12(5), 391-396.

Epley, N. y Gilovich, T. (2006). The anchoring-and-adjustment heuristic: Why the adjustments are insufficient. Psychological Science, 17(4), 311-318.

Epley, N. y Gilovich, T. (2010). Anchoring unbound. Journal of Consumer Psychology, 20(1), 20-24.

Epstein, L. y Schneider, M. (2010). Ambiguity and asset markets. Annual Review of Financial Economics, 2, 315-346. 
Erceg, N. y Galic, Z. (2014). Overconfidence bias and conjunction fallacy in predicting outcomes of football matches. Journal of Economic Psychology, 42, 52-62.

Etner, J., Jeleva, M. y Tallon, J. (2012). Decision theory under ambiguity. Journal of Economic Surveys, 26(2), 234-270.

Falk, A., Fehr, E. y Fischbacher, U. (2003). On the nature of fair behavior. Economic Inquiry, 41(1), 20-26.

Fellner, G. y Sutter, M. (2009). Causes, consequences, and cures of myopic loss aversion: An experimental investigation. The Economic Journal, 119, 900-916.

Fellner, W. (1961). Distortion of subjective probabilities as a reaction to uncertainty. Quarterly Journal of Economics, 75(4), 670-690.

Festinger, L. (1957). A theory of cognitive dissonance. Stanford University Press.

Finucane, M., Alhakami, A., Slovic, P. y Johnson, M. (2000). The affect heuristic in judgments of risks and benefits. Journal of Behavioral Decision Making, 13(1), 1-17.

Fischhoff, B. (1982). For those condemned to study the past: Heuristics and biases in hindsight. Kahneman, D., Slovic, P. y Tversky, A. Judgment under uncertainty: Heuristics and biases, Cambridge University Press.

Frankel, J. y Schreger, J. (2013). Over-optimistic official forecasts and fiscal rules in the Eurozone. Review of World Economics, 149(2), 247-272.

Frederick, S. (2005). Cognitive reflection and decision making. Journal of Economic Perspectives, 19(4), $25-42$.

Frederick, S., Kahneman, D. y Mochon, D. (2010). Elaborating a simpler theory of anchoring. Journal of Consumer Psychology, 20(1), 17-19. 
Frederick, S., Loewenstein, G. y O'Donoghe, T. (2002). Time discounting and time preference: A critical review. Journal of Economic Literature, 40(2), 351-401.

Füllbrunn, S., Rau, H. y Weitzel, U. (2014). Does ambiguity aversion survive in experimental asset markets? Journal of Economic Behavior \& Organization, 107(b), 810-826.

Furnham, A. y Boo, H. (2011). A literature review on the anchoring effect. The Journal of Socio-Economics, $40(1), 35-42$.

Gatherwood, J. y Weber, J. (2014). Self-control, financial literacy and the co-holding puzzle. Journal of Economic Behavior \& Organization, 107(b), 455-469.

Gennaioli, N. y Shleifer, A. (2010). What comes to mind. The Quarterly Journal of Economics, 125(4), 1399-1433.

Gettys, C., III, K. y Peterson, C. (1973). The best-guess hypothesis in multistage inference. Organizational Behavior and Human Performance, 10(3), 364-373.

Gianneti, M. y Yafeh, Y. (2012). Do cultural differences between contracting parties matter? Evidence from syndicated bank loans. Management Science, 58(2), 365-383.

Gigerenzer, G. (1991). How to make cognitive illusions disappear: Beyond 'heuristics and biases'. Stroebe y Hewstone, M, (edits.), European Review of Social Psychology. Wiley.

Gigerenzer, G. y Goldstein, D. (1996). Reasoning the fast and frugal way: Models of bounded rationality. Psychological Review, 103(4), 650-669.

Gigerenzer, G. y Goldstein, D. (1999). Betting on one good reason: The take the best heuristic. Simple Heuristics That Make Us Smart. Oxford University Press.

Gigerenzer, G. y Goldstein, D. (2011). The recognition heuristic: A decade of research. Judgment and Decision Making, 6(1), 100-121. 
Gigerenzer, G. y Gaissmaier, W. (2011). Heuristic decision making. Annual Review of Psychology 62, 451-482, http://ssrn.com/abstract=1722019

Gigerenzer, G., Hoffrage, U. y Kleinbölting, H. (1991). Probabilistic mental models: A Brunswikian theory of confidence. Psychological Review, 98(4), 506-528.

Gilbert, P., Price, J. y Allan, S. (1995). Social comparison, social attractiveness and evolution: How might they be related? New Ideas in Psychology, 13(2), 149-165.

Gilovich, T. y Griffin, D. (2002). Introduction - Heuristics and Biases: Then and now. Gilovich, T., Griffin, D. y Kahneman, D. (edits.), Heuristics and biases: The psychology of intuitive judgment. Cambridge University Press.

Gneezy, U., Kapteyn, A. y Potters, J. (2003). Evaluation periods and asset prices in a market experiment. Journal of Finance, 58(2), 821-837.

Goldstein, D. y Gigerenzer, G. (1999). The recognition heuristic: How ignorance makes us smart. Simple heuristics that make us smart, (pp. 37-58). New York: Oxford University Press.

Goldstein, D. y Gigerenzer, G. (2002). Models of ecological rationality: The recognition heuristic. Psychological Review, 109(4), 75-90.

Grieco, D. y Hogarth, R. (2009). Overconfidence in absolute and relative performance: The regression hypothesis and Bayesian updating. Journal of Economic Psychology, 30(5), 756-771.

Griffin, D. y Tversky, A. (1992). The weighing of evidence and the determinants of confidence. Cognitive Psychology, 24(3), 411-435.

Griffin, D. y Brenner, L. (2004). Perspectives on probability judgment calibration. Koehler, D. y Harvey, N. (edits.), Blackwell Handbook of Judgment and Decision Making, pp. 177-199. Wiley. 
Griffin, D., Gonzalez, R. Koehler, D. y Gilovich, T. (2012), Judgmental heuristics: A historical overview. Holyoak, K. y Morrison, R. (edits.). The Oxford Handbook of Thinking and Reasoning, (pp. 322-345). Oxford University Press.

Griffith, R. (1949). Odds adjustments by American horse-race bettors. The American Journal of Psychology, 62(2), 290-294.

Grinblatt, M. y Keloharju, M. (2009). Sensation seeking, overconfidence and trading activity. The Journal of Finance, 64(2), 549-578.

Guiso, L., Sapienza, P. y Zingales, L. (2006). Does culture affect economic outcomes? Journal of Economic Perspectives, 20(2), 23-48.

Gurevich, G., Kliger, D. y Weiner, B. (2012). The role of attribution of causality in economic decision making. The Journal of Socio-Economics, 41(4), 439-444.

Güth, W., Schmittberger, R. y Schwarze, B. (1982). An experimental analysis of ultimatum bargaining. Journal of Economic Behavior and Organization, 3(4), 367-388.

Haack, P., Pfarrer, M. y Scherer, A. (2014). Legitimacy-as-feeling: How affect leads to vertical legitimacy spillovers in transnational governance. Journal of Management Studies, 51(4), 634-666.

Haisley, E., Mostafa, R. y Loewenstein, G. (2008). Myopic risk-seeking: The impact of narrow decision bracketing on lottery play. Journal of Risk and Uncertainty, 37(1), 57-75.

Hansen, P., Hendricks, V. y Rendsvig, R. (2013). Infostorms. Metaphilosophy, 44(3), 301-326.

Hardin, A. y Looney, A. (2012). Myopic loss aversion: Demystifying the key factors influencing decision problem framing. Organizational Behavior and Human Decision Processes, 117(2), 311-331.

Heath, C., Larrick, R. y Klayman, J. (1998). Cognitive repairs: How organizational practices can compensate for individual shortcomings. Research in Organizational Behavior, 20, 1-37. 
Heffetz, O. y Frank, R. (2011). Preferences for status: Evidence and economic implications. Benhabib, J. Bisin, A. y Jackson, M. (edits.), Handbook of social economics, (pp. 69-91). North-Holland,

Helson, H. (1964). Adaptation level theory: An experimental and systematic approach to behavior. Harper \& Row.

Hendricks, D., Patel, J. y Zeckhauser, R. (1993). Hot hands in mutual funds: Short-run persistence of relative performance, 1974-1988. Journal of Finance, 48(1), 93-130.

Henrich, J., Boyd, R., Bowles, S., Camerer, C., Gintis, H., McElreath, R. y Fehr, E. (2001). In search of Homo economicus: Behavioral experiments in 15 small-scale societies. American Economic Review, 91(2), 73-79.

Hens, T. y Bachmann, K. (2008). Behavioral finance for private banking. John Wiley \& Sons.

Hirshleifer, D. (2001). Investor psychology and asset pricing. Journal of Finance, 56(4), 1533-97.

Hirshleifer, D. (2008). Psychological bias as a driver of financial regulation. European Financial Management, 14(5), 856-874.

Hirshleifer, D. (2015). Behavioral finance. Annual Review of Financial Economics, 7(7), 133-159.

Hirshleifer, D. y Teoh, S. (2003). Limited attention, information disclosure and financial reporting. Journal of Accounting and Economics, 36(1), 337-386.

Hirshleifer, D., Hou, K. y Teoh, S. (2012). The accrual anomaly: Risk or mispricing. Management Science, $58(2), 320-335$.

Hodges, S., Tompkins, R. y Ziemba, W. (2008). The favorite longshot bias in S\&P 500 and FTSE 100 Index futures options: The return to bets and the cost of insurance. Handbook of Sports and Lottery Markets. Elsevier. 
Hoff, K. y Stiglitz, J. (2010). Equilibrium fictions: A cognitive approach to societal rigidity. American Economic Review, 100(2), 141-146.

Hoff, K. y Priyanka, P. (2004). Belief systems and durable inequalities: An experimental investigation of Indian caste. World Bank Working Paper 3351.

Hoffrage, U., Hertwig, R. y Gigerenzer, G. (2000). Hindsight bias: A by-product of knowledge updating? Journal of Experimental Psychology: Learning, Memory and Cognition, 26(3), 566-581.

Hoppe, E. y Kusterer, J. (2011). Behavioral biases and cognitive reflection. Economic Letters, 110 (2), 97-100.

Hossain, T. y List, J. (2012). The behavioralist visits the factory: Increasing productivity using simple framing manipulations. Management Science, 58(12), 2151-2167.

Hu, Y. y Li, X. (2011). Context-dependent product evaluations: An empirical analysis of internet book reviews. Journal of Interactive Marketing, 25(3), 123-133.

Huber, J., Payne, J. y Puto, C. (1982). Adding asymmetrically dominated alternatives: Violations of regularity and similarity hypothesis. Journal of Consumer Research, 9(1), 90-98.

Huber, J., Kirchler, M. y Stöckl, T. (2010). The hot hand belief and the gambler's fallacy in investment decisions under risk. Theory and Decision, 68(4), 445-462.

Huberman, G. (2001). Familiarity breeds investment. The Review of Financial Studies, 14(3), 659-680.

Ilomäki, J. (2012). Framed field experiment with stock market professionals. The Journal of Behavioral Finance, 13(4), 251-258.

Jacobsen, B., Lee, J. Marquering, W. y Zhang, C. (2014). Gender differences in optimism and asset allocation. Journal of Economic Behavior \& Organization, 107(b), 630-651. 
Janis, I. (1972). Victims of Groupthink. Houghton Mifflin.

Jaspersen, J. y Aseervatham, V. (2015). The influence of affect on heuristic thinking in insurance demand. The Journal of Risk and Insurance. https://doi.org/10.1111/jori.12088

Ji, L., Nisbett, R. y Su, Y. (2001). Culture, change, and prediction. Psychological Science, 12(6), 450-456.

Kahneman, D. (2003a). Maps of bounded rationality: Psychology for Behavioral Economics. The American Economic Review, 93(5), 1449-75.

Kahneman, D. (2003b). A perspective on judgment and choice: Mapping bounded rationality. American Psychologist, 58(9), 697-720.

Kahneman, D. y Tversky, A. (1972). Subjective probability: A judgment of representativeness. Cognitive Psychology, 3, 430-454.

Kahneman, D. y Tversky, A. (1979). Prospect theory: An analysis of decision under risk. Econometrica, 47(2), 263-292.

Kahneman, D. y Tversky, A. (1982). The simulation heuristic. Kahneman, D., Slovic, P. y Tversky, A. (edits.). Judgment under uncertainty: heuristics and biases. Cambridge University Press.

Kahneman, D. y Tversky, A. (1984). Choices, values and frames. American Psychologist, 39(4), 341-350.

Kahneman, D. y Tversky, A. (1996). On the reality of cognitive illusions. Psychological Review, 103(3), 582-591.

Kahneman, D. y Lovallo, D. (1993). Timid choices and bold forecasts: A cognitive perspective on risk taking. Management Science, 39(1), 17-31.

Kahneman, D. y Riepe, M. (1998). Aspects of investor psychology. Journal of Portfolio Management, 24(4), 52-65. 
Kahneman, D. y Frederick, S. (2002). Representativeness revisited: Attribute substitution in intuitive judgment. Gilovich, T., Griffin, D. y Kahneman, D. (edits.), Heuristics and biases: The psychology of intuitive thought, (pp. 49-81). Cambridge University Press.

Kahneman, D. y Frederick, S. (2005). A model of heuristic judgment. Holyoake, KJ y Morrison, R. (edits.). The Cambridge Handbook of Thinking and Reasoning. Cambridge University Press.

Kahneman, D., Knetsch, J. y Thaler, R. (1986a). Fairness as a constraint on profit seeking: Entitlements in the market. American Economic Review, 76(4), 728-741.

Kahneman, D., Knetsch, J. y Thaler, R. (1986b). Fairness and the assumptions of Economics. Journal of Business, 59(4), S285-S300.

Kahneman, D., Knetsch, J. y Thaler, R. (1990). Experimental tests of the endowment effect and the Coase Theorem. Journal of Political Economy, 98(6), 1325-48.

Kahneman, D., Knetsch, J. y Thaler, R. (1991). Anomalies: The endowment effect, loss aversion, and status quo bias. The Journal of Economic Perspectives, 5(1), 193-206.

Kahneman, D., Slovic, P. y Tversky, A. (1982). Judgment Under Uncertainty: Heuristics and Biases. Cambridge University Press.

Katona, G. (1901). Psychological Economics. Elsevier (1975).

Kirby, K. y Herrnstein, R. (1995). Preference reversals due to myopic discounting of delayed reward. Psychology Science, 6(2), 83-89.

Knetsch, J. (1989). The endowment effect and evidence of nonreversible indifference curves. The American Economic Review, 79(5), 1277-84.

Koch, A. y Nafzinger, J. (2016). Goals and bracketing under mental accounting. Journal of Economic Theory, 162(c), 305-361. 
Koop, G. y Johnson, J. (2012). The use of multiple reference points in risky decision making. Journal of Behavioral Decision Making, 25, 49-62.

Kõszegi, B. y Rabin, M. (2006). A model of reference-dependent preferences. Quarterly Journal of Economics, 121(4), 1133-65.

Kõszegi, B. y Rabin, M. (2007). Reference-dependent risk attitudes. The American Economic Review, 97(4), 1047-73.

Kumar, A. y Lim, S. (2008). How do decision frames influence the stock investment decisions of individual investors? Management Science, 54(6), 1052-1064.

Kuran, T. y Sunstein, C. (1999). Availability cascades and risk regulation. Stanford Law Review, 51(4), 683-768.

Lacetera, N., Pope, D. y Sydnor, J. (2014). Heuristic thinking and limited attention in the car market. American Economic Review, 102(5), 2206-2236.

Lahvicka, J. (2014). What causes the favourite-longshot bias? Further evidence from tennis. Applied Economic Letters, 21(2), 90-92.

Landman, J. y Manis, M. (1983). Social cognition: Some historical and theoretical perspectives. Advances in Experimental Social Psychology, 16, 49-123.

Langer, E. (1975). The illusion of control. The Journal of Personality and Social Psychology, 32(2), 311-328.

Langer, T. y Weber, M. (2005). Myopic prospect theory vs. myopic loss aversion: How general is the phenomenon? Journal of Economic Behavior \& Organization, 56(1), 25-38.

Lee, C. y Andrade, E. (2011). Fear, social projection, and financial decision making. Journal of Marketing Research, 48, S121-S129. 
Lejarraga, T. y Gonzalez, C. (2011). Effects of feedback and complexity on repeated decisions from description. Organizational Behavior and Human Decision Processes, 116(2), 286-295.

Levinson, J. y Peng, K. (2007). Valuing cultural differences in Behavioral Economics. The ICFAI Journal of Behavioral Finance, 4(1), 32-47.

Libby, R. y Rennekamp, K. (2012). Self-serving attribution bias, overconfidence, and the issuance of management forecasts. Journal of Accounting Research, 50(1), 197-231.

Liberali, J., Reyna, V., Furlan, S., Stein, L. y Pardo, S. (2012). Individual differences in numeracy and cognitive reflection, with implications for biases and fallacies in probability judgments. Journal of Behavioral Decision Making, 25(4), 361-381.

Lichtenstein, S. y Fischhoff, B. (1977). Do those who know more also know more about how much they know? Organizational Behavior and Human Performance, 20(2), 159-183.

List, J. (2007). On the interpretation of giving in dictator games. Journal of Political Economy, 115(3), 482-493.

Liu, H. y Colman, A. (2009). Ambiguity aversion in the long run: Repeated decisions under risk and uncertainty. Journal of Economic Psychology, 30(3), 277-284.

Liu, Y., Huang, Y., Luo, Y. y Zhao, Y. (2014). How does justice matter in achieving buyer-supplier relationship performance? Journal of Operations Management, 30, 355-367.

Lo, A., Repin, D. y Steenbarger, B. (2005). Fear and greed in financial markets: A clinical study of daytraders. The American Economic Review, 95(2), 352-359.

Loewenstein, G. (1996). Out of control: Visceral influences on behavior. Organizational Behavior and Human Decision Processes, 65(3), 272-292. 
Loewenstein, G., Weber, E., Hsee, C. y Welch, N. (2001). Risk as feelings. Psychological Bulletin, 127(2), 267-86.

Loewenstein, G., O'Donoghue, T. y Rabin, M. (2003). Projection bias in predicting future utility. Quarterly Journal of Economics, 118(4), 1209-48.

Lord, C., Ross, L. y Lepper, M. (1979). Biased assimilation and attitude polarization: The effects of prior theories on subsequently considered evidence. Journal of Personality \& Social Psychology, 37(11), 2098-2109.

Lovallo, D. y Kahneman, D. (2003). Delusions of success: How optimism undermines executives' decisions. Harvard Business Review, 81(7), 56-63.

Lundeberg, M., Fox, P. y Punccohar, J. (1994). Highly confident but wrong: Gender differences and similarities in confidence judgments. Journal of Educational Psychology, 86(1), 114-121.

Lunenburg, F. (2010). Group decision making: The potential for groupthink. International Journal of Management, Business, and Administration, 13(1), 1-6.

Malmendier, U. y Tate, G. (2005a). CEO overconfidence and corporate investment. Journal of Finance, 60(6), 2661-2700.

Malmendier,U. y Tate, G. (2005b). Does overconfidence affect corporate investment? CEO Overconfidence measures revisited. European Financial Management, 11(5), 649-659.

Manski, C. (2000). Economic analysis of social interactions. Journal of Economic Perspectives, 14(3), 115-136.

Marewski, J., Gaissmaier, W. y Gigerenzer, G. (2010). Good judgments do not require complex cognition. Cognitive Processing, 11(2), 103-121. 
Mayo-Wilson, C., Zollman, K. y Danks, D. (2012). Wisdom of crowds versus groupthink: learning in groups and in isolation. International Journal of Game Theory, 42(3), 695-723.

McGraw, A., Larsen, J., Kahneman, D. y Schkade, D. (2010). Comparing gains and losses, Psychological Science, 21(10), 1438-45.

Milgram, S. (1963). Behavioral study of obedience. The Journal of Abnormal and Social Psychology, 67(4), 371-378.

Milgram, S. (1974). Obedience to authority: An experimental view. HarperCollins.

Miller, J. (1984). Culture and the development of everyday social explanation. Journal of Personality and Social Psychology, 46(5), 961-978.

Moore, D. y Healy, P. (2008). The trouble with overconfidence. Psychological Review, 115(2), 502-517.

Mullainathan, S. y Thaler, R. (2000). Behavioral Economics. MIT Dept. of Economics Working Paper No. 00-27. http://ssrn.com/abstract $=245828$

Nguyen, B. y Klaus, P. (2013). Retail fairness: Exploring consumer perceptions of fairness towards retailers' marketing tactics. Journal of Retailing and Consumer Services, 20(3), 311-324.

Nisbett, R. y Masuda, T. (2003). Culture and point of view. Proceedings of the National Academy of Science, 100(19), 11163-70.

Nofsinger, J. (2012). Household behavior and boom/bust cycles. Journal of Financial Stability, 8(3), 161-173.

Novemsky, N. y Kahneman, D. (2005). The boundaries of loss aversion. Journal of Marketing Research, 42(2), 119-128.

Odean, T. (1998a). Are investors reluctant to realize their losses? Journal of Finance, 53(5), 1775-98. 
Odean, T. (1998b), Volume, volatility, price and profit when all traders are above average. Journal of Finance, 53(6), 1887-1934.

Odean, T. (1999). Do investors trade too much? The American Economic Review, 89(5), 1279-1298.

Oechssler, J., Roider, A. y Schmitz, P. (2009). Cognitive abilities and behavioral biases. Journal of Economic Behavior \& Organization, 72(1), 147-152.

Okun, A. (1981). Prices and quantities: A macro-economic analysis. The Brookings Institution.

Oppenheimer, D., Leboeuf, R. y Brewer, N. (2008). Anchors aweigh: A demonstration of cross-modality anchoring and magnitude priming. Cognition, 106(1), 13-26.

Ortmann, A., Gigerenzer, G., Borges, B. y Goldstein, D. (2008). The recognition heuristic: A fast and frugal way to investment choice? Plott, C. y Smith, V. (edits.). Handbook of experimental economics results: vol 1, (pp. 993-1003). Handbooks in Economics 28.

Oskamp, S. (1965). Overconfidence in case-study judgments. The Journal of Consulting Psychology, 29(3), 261-265.

Ottaviani, M. y Sorensen, P. (2007). The favorite-longshot bias: An overview of the main explanations. Hausch, D. y Ziemba, W. (edits.). Efficiency of Sports and Betting Markets. Elsevier: Handbook in Finance Series.

Pacheco, J. (2012). The social contagion model: Exploring the role of public opinion on the diffusion of antismoking legislation across the American States. The Journal of Politics, 74(1), 187-202.

Pachur, T. y Galesic, M. (2013). Strategy selection in risky choice: The impact of numeracy, affect, and cross-cultural differences. Journal of Behavioral Decision Making, 26(3), 260-271.

Page, L. y Clemen, R. (2013). Do prediction markets produce well-calibrated probability forecasts? The Economic Journal, 123(568), 491-513. 
Pan, C. y Statman, M. (2010). Beyond risk tolerance: Regret, overconfidence and other investor propensities. SCU Leavey School of Business, Research Paper No. 10-05.

Pennycook, G. y Thompson, V. (2012). Reasoning with base rates is routine, relatively effortless, and context dependent. Psychonomic Bulletin \& Review, 19(3), 528-534.

Pennycook, G., Trippas, D., Handley, S. y Thompson, V. (2014). Base rates: Both neglected and intuitive. Journal of Experimental Psychology: Learning, Memory and Cognition, 40(2), 544-554.

Peón, D., Antelo, M. y Calvo, A. (2015). A dynamic behavioral model of the credit boom. Journal of Economic Issues, 49(4), 1077-99.

Phelps, E. y Pollak, R. (1968). On second-best national saving and game-equilibrium growth. Review of Economic Studies, 35(2), 185-199.

Plous, S. (1991). Biases in the assimilation of technological breakdowns: Do accidents make us safer? Journal of Applied Social Psychology, 221(13), 1058-82.

Plous, S. (1993). The Psychology of Judgment and Decision Making. McGraw-Hill.

Polman, E. (2012). Self-other decision making and loss aversion. Organizational Behavior and Human Decision Processes, 119(2), 141-150.

Pool, V., Stoffman, N. y Yonker, S. (2012). No place like home: Familiarity in mutual fund manager portfolio choice. The Review of Financial Studies, 25(8), 2563-99.

Prendergast, C. y Stole, L. (1996). Impetuous youngsters and jaded old-timers: Acquiring a reputation for learning. Journal of Political Economy, 104(6), 1105-34.

Presson, P. y Benassi, V. (1996). Illusion of control: A meta-analytic review. Journal of Social Behavior and Personality, 11(3), 493-510. 
Prince, M. (1993). Women, men, and money stiles. Journal of Economic Psychology, 14(1), 175-182.

Rabin, M. (1998). Psychology and Economics. Journal of Economic Literature, 36(1), 11-46.

Rabin, M. (2000). Risk aversion and expected-utility theory: A calibration theorem. Econometrica, 68(5), 1281-92.

Rabin, M. (2002a). A perspective on Psychology and Economics. European Economic Review, 46(4-5), 657-685.

Rabin, M. (2002b). Inference by believers in the Law of Small Numbers. Quarterly Journal of Economics, $117(3), 775-816$.

Rabin, M. y Vayanos, D. (2010). The gambler's and hot-hand fallacies: Theory and applications. Review of Economic Studies, 77(2), 730-778.

Rabin, M. y Schrag, J. (1999). First impressions matter: A model of confirmatory bias. Quarterly Journal of Economics, 114(1), 37-82.

Rapp, A., Beitelspacher, L., Grewal, D. y Hughes, D. (2013). Understanding social media effects across seller, retailer, and consumer interactions. Journal of the Academy of Marketing Science, 47(5), 547-566.

Read, D., Loewenstein, G. y Rabin, M. (1999). Choice bracketing. Journal of Risk and Uncertainty, 19(1-3), 171-197.

Ricciardi, V. y Simon, H. (2000). What is Behavioral Finance? Business, Education \& Technology Journal, 2(2), 1-9.

Richins, M. (1991). Comparison and the idealized images of advertising. Journal of Consumer Research, 18(1), 71-83. 
Rieger, M. (2012). Why do investors buy bad financial products? Probability misestimation and preferences in financial investment decision. Journal of Behavioral Finance, 13(2), 108-118.

Roca, M., Hogarth, R. y Maule, J. (2006). Ambiguity seeking as a result of the status quo bias. Journal of Risk and Uncertainty, 32(3), 175-194.

Roese, N. y Vohs, K. (2012). Hindsight bias. Perspectives on Psychological Science, 7(5), 411-426.

Roll, R. (1986), The hubris hypothesis of corporate takeovers, Journal of Business 59(2), 197-216.

Rooderkerk, R., van Heerde, H. y Bijmolt, T. (2011). Incorporating context effects into a choice model. Journal of Marketing Research, 48(4), 767-780.

Ross, M. y Sicoly, F. (1977). Egocentric biases in availability and attribution. Judgment under uncertainty: heuristics and biases. Cambridge University Press.

Rubin, J. (2014). Centralized institutions and cascades. Journal of Comparative Economics, 42(2), 340357.

Sahi, S., Arora, A. y Dhameja, N. (2013). An exploratory inquiry into the psychological biases in financial investment behavior. Journal of Behavioral Finance, 14(2), 94-103.

Salovey, P. y Rodin, J. (1984). Some antecedents and consequences of social-comparison jealousy. Journal of Personality and Social Psychology, 47(4), 780-792.

Samuelson, W. y Zeckhauser, R. (1988). Status quo bias in decision making. Journal of Risk and Uncertainty, 1(1), 7-59.

Scheinkman, J. y Xiong, W. (2003). Overconfidence and speculative bubbles. Journal of Political Economy, 111(6), 1183-1219. 
Schlüter, A. y Vollan, B. (2015). Flowers and an honour box: Evidence on framing effects. Journal of Behavioral and Experimental Economics, 57, 186-199.

Schmidt, U. y Zank, H. (2012). A genuine foundation for prospect theory. Journal of Risk and Uncertainty, 45(2), 97-113.

Scholten, M. y Read, D. (2006). Discounting by intervals: A generalized model of intertemporal choice. Management Science, 52(9), 1424-36.

Schooler, L. y Hertwig, R. (2005). How forgetting aids heuristic inference. Psychological Review, 112(3), 610-628.

Schwager, S. y Rothermund, K. (2013). Motivation and affective processing biases in risky decision making: A counter-regulation account. Journal of Economic Psychology, 38, 111-126.

Schwikert, S. y Curran, T. (2014). Familiarity and recollection in heuristic decision making. Journal of Experimental Psychology, 143(6), 2341-65.

Seiler, M., Seiler, V., Harrison, D. y Lake, M. (2013). Familiarity bias and perceived future home price movements. Journal of Behavioral Finance, 14(1), 9-24.

Sen, A. (1995). Moral codes and economic success. Brittan, C. y Hamlin, A. (edits.) Market Capitalism and Moral Values. Aldershot.

Shafir, E. y Thaler, R. (2006). Invest now, drink later, spend never: The mental accounting of delayed consumption. Journal of Economic Psychology, 27(5), 694-712.

Shefrin, H. (2000). Beyond Greed and Fear: Understanding Behavioral Finance and the Psychology of Investing. (Segunda edición). Oxford University Press.

Shefrin, H. (2006). Behavioral Corporate Finance. McGraw-Hill. 
Shefrin, H. y Cervellati, E. (2011). BP's failure to debias: Underscoring the importance of behavioral corporate finance. Quarterly Journal of Finance, 1(1), 127-168.

Shefrin, H. y Statman, M. (1985). The disposition to sell winners too early and ride losers too long: Theory and evidence. Journal of Finance, 40(3), 777-790.

Shefrin, H. y Statman, M. (2000). Behavioral portfolio theory. Journal of Financial and Quantitative Analysis, 35(2), 127-151.

Sherif, M. (1937). An experimental approach to the study of attitudes. Sociometry 1, 90-98.

Shiller, R. (1984). Stock prices and social dynamics. Brookings Papers on Economic Activity. Fall: 457498.

Shiller, R. (2000a). Human behavior and the efficiency of the financial system. Taylor, B. y Woodfood, M. (edits.). Handbook of Macroeconomics. North Holland.

Shiller, R. (2000b). Irrational exuberance. Princeton University Press.

Shiller, R. (2003). From efficient market theory to behavioral finance. Journal of Economic Perspectives, 17(1), 83-104.

Shin, H. (1992). Prices of state contingent claims with insider traders, and the favorite-longshot bias. The Economic Journal, 102(411), 426-435.

Shleifer, A. (2000). Inefficient Markets: An Introduction to Behavioral Finance. Oxford University Press.

Shleifer, A. (2004). Does competition destroy ethical behavior? American Economic Association Papers and Proceedings, 94(2), 414-418.

Simon, H.A. (1957). Models of Man: Social and Rational. Wiley. 
Simonson, I. (1989). Choice based on reasons: The case of attraction and compromise effects. Journal of Consumer Research, 16(2), 158-74.

Simonson, I. y Tversky, A. (1992). Choice in context: Tradeoff contrast and extremeness aversion. Journal of Marketing Research, 29(3), 281-295.

Slovic, P., Finucane, M., Peters, E. y MacGregor, D. (2002). The affect heuristic. Gilovich, T., Griffin, D. y Kahneman, D. (edits.), Heuristics and Biases: The Psychology of Intuitive Judgment, (pp. 387-420). Cambridge University Press.

Solow, R. (1980). On theories of unemployment. American Economic, Review, 70(1), 1-11.

Statman, M. (1999). Behavioral finance: Past battles, future engagements. Financial Analysts Journal, 55(6), 18-27.

Statman, M. y Weng, J. (2010). Investment across cultures: Financial Attitudes of Chinese-Americans. Journal of Investment Consulting, 11(1), 37-44.

Statman, M., Thorley, S. y Vorkink, K. (2006). Investor overconfidence and trading volume. The Review of Financial Studies, 19(4), 1531-65.

Stevens, J. (2016). Intertemporal similarity: Discounting as a last resort. Journal of Behavioral Decision Making, 29(1), 12-24.

Stöckl, T., Huber, J., Kirchler, M. y Lindner, F. (2015). Hot hand and gambler's fallacy in teams: Evidence from investment experiments. Journal of Economic Behavior \& Organization, 117(11), 327-339.

Strotz, R. (1955). Myopia and inconsistency in dynamic utility maximization. Review of Economic Studies, 23(3), 165-180.

Stulz, R. y Williamson, R. (2003). Culture, openness, and finance. Journal of Financial Economics, 70(3), 313-349. 
Suetens, S. y Tyran, J. (2012). The gambler's fallacy and gender. Journal of Economic Behavior \& Organization, 83(1), 118-124.

Sul, S., Kim, J. y Choi, I. (2013). Subjective well-being and hedonic editing: How happy people maximize joint outcomes of loss and gain. Journal of Happiness Studies, 14(4), 1409-1430.

Taylor, M. y Wilson, S. (2012). Does culture still matter? The effects of individualism on national innovation rates. Journal of Business Venturing, 27(2), 234-247.

Taylor, S. (1982). The availability bias in social perception and interaction. Kahneman, D. Slovic, P. y Tversky, A. Judgment under uncertainty: heuristics and biases. Cambridge University Press.

Thaler, R. (1983). Illusions and mirages in public policy. Public Interest, 73, 60-74.

Thaler, R. (1985). Mental accounting and consumer choice. Marketing Science, 4(3), 199-214.

Thaler, R. (1999). Mental accounting matters. Journal of Behavioral Decision Making, 12(3), 183-206.

Thaler, R. (2008). Mental accounting and consumer choice: Anatomy of a failure. Marketing Science, 27(1), 12-14.

Thaler, R. y Johnson, E. (1990). Gambling with the house money and trying to break even: The effects of prior outcomes on risky choice. Management Science, 36(6), 643-660.

Thaler, R. y Shefrin, H. (1981). An economic theory of self-control. Journal of Political Economy, 89(2), 392-406.

Thaler, R., Tversky, A., Kahneman, D. y Schwartz, A. (1997). The effect of myopia and loss aversion on risk: Taking an experimental test. Quarterly Journal of Economics, 112(2), 646-661.

Trivers, R. (1971). The evolution of reciprocal altruism. Quarterly Review of Biology, 46(1), 35-57. 
Troye, S. y Supphellen, M. (2012). Consumer participation in coproduction: "I made it myself" effects on consumers' sensory perceptions and evaluations of outcome and input product. Journal of Marketing, 76(2), 33-46.

Tsetsos, K., Chater, N. y Usher, M. (2012). Salience driven value integration explains decision biases and preference reversal. Proceedings of the National Academy of Sciences of the United States of America, 109(24), 9659-64.

Tversky, A. (1972). Elimination by aspects: A theory of choice. Psychological Review, 79(4), 281-99.

Tversky, A. y Kahneman, D. (1971). The belief in the law of small numbers. Psychological Bulletin, 76(2), 105-110.

Tversky, A. y Kahneman, D. (1973). Availability: A heuristic for judging frequency and probability, Cognitive Psychology 5(2), 207-232.

Tversky, A. y Kahneman, D. (1974). Judgment under uncertainty: Heuristics and biases. Science, 185(4157), 1124-31.

Tversky, A. y Kahneman, D. (1981). The framing of decisions and the psychology of choice. Science, 211(4481), 453-458.

Tversky, A. y Kahneman, D. (1982a). Evidential impact of base rates. Judgment under uncertainty: Heuristics and biases. Cambridge University Press.

Tversky, A. y Kahneman, D. (1982b). Judgments of and by representativeness. Judgment under uncertainty: Heuristics and biases. Cambridge University Press.

Tversky, A. y Kahneman, D. (1983). Extension versus intuitive reasoning: The conjunction fallacy in probability judgment. Psychological Review, 90(4), 293-315. 
Tversky, A. y Kahneman, D. (1986). Rational choice and the framing of decisions. The Journal of Business, 59(S4), S251-S278.

Tversky, A. y Kahneman, D. (1991). Loss aversion in riskless choice: A reference-dependent model. The Quarterly Journal of Economics, 106(4), 1039-61.

Tversky, A. y Kahneman, D. (1992). Advances in prospect theory: Cumulative representation of uncertainty. Journal of Risk and Uncertainty, 5(4), 297-323.

Tversky, A. y Simonson, I. (1993). Context-dependent preferences. Management Science, 39(10), 1179-89.

Weber, M. (1905). The Protestant Ethic and the Spirit of Capitalism. Routledge Classic.

Weiner, B. (1985). An attributional theory of achievement motivation and emotion. Psychological Review, 92(4), 548-573.

Williams, E. y Gilovich, T. (2008). Do people really believe they are above average? Journal of Experimental Social Psychology, 44(4), 1121-28.

Wu, J. (2015). Helpful laymen in informational cascades. Journal of Economic Behavior \& Organization, 116(c), 407-415.

Zeisberger, S., Vrecko, D. y Langer, T. (2015). Measuring time stability of prospect theory preferences. Theory and Decision, 72(3), 359-386.

Zhang, X.-J. (2013). Book-to-Market ratio and skewness of stock returns. The Accounting Review, 88(6), 2213-40. 